\title{
A Functional Comparison of Homopentameric Nicotinic Acetylcholine Receptors (ACR-16) Receptors From Necator americanus and Ancylostoma ceylanicum
}

\author{
Mark D. Kaji' ${ }^{1}$, Timothy G. Geary ${ }^{1,2}$ and Robin N. Beech ${ }^{1 *}$ \\ 1 Institute of Parasitology, McGill University, Montreal, QC, Canada, ${ }^{2}$ School of Biological Sciences, Queen's \\ University-Belfast, Belfast, United Kingdom
}

\section{OPEN ACCESS}

Edited by:

Helene Tricoire-Leignel,

Université d'Angers, France

Reviewed by:

Cecilia Bouzat,

National University of the South,

Argentina

David J. Adams,

University of Wollongong, Australia

*Correspondence:

Robin N. Beech

robin.beech@mcgill.ca

Received: 31 August 2020 Accepted: 04 November 2020 Published: 26 November 2020

Citation:

Kaji MD, Geary TG and Beech RN (2020) A Functional Comparison

of Homopentameric Nicotinic Acetylcholine Receptors (ACR-16) Receptors From Necator americanus

and Ancylostoma ceylanicum

Front. Mol. Neurosci. 13:601102. doi: 10.3389/fnmol.2020.601102
Effective control of hookworm infections in humans and animals relies on using a small group of anthelmintics. Many of these drugs target cholinergic ligand-gated ion channels, yet the direct activity of anthelmintics has only been studied in a subset of these receptors, primarily in the non-parasitic nematode, Caenorhabditis elegans. Here we report the characterization of a homopentameric ionotropic acetylcholine receptor (AChR), ACR-16, from Necator americanus and Ancylostoma ceylanicum, the first known characterization of human hookworm ion channels. We used twoelectrode voltage clamp electrophysiology in Xenopus laevis oocytes to determine the pharmacodynamics of cholinergics and anthelmintics on ACR-16 from both species of hookworm. The A. ceylanicum receptor (Ace-ACR-16) was more sensitive to acetylcholine $\left(E_{50}=20.64 \pm 0.32 \mu \mathrm{M}\right)$ and nicotine $\left(E_{50}=24.37 \pm 2.89 \mu \mathrm{M}\right)$ than the $N$. americanus receptor (Nam-ACR-16) (acetylcholine $\mathrm{EC}_{50}=170.1 \pm 19.23 \mu \mathrm{M}$; nicotine $\left.E_{50}=597.9 \pm 59.12 \mu \mathrm{M}\right)$, at which nicotine was a weak partial agonist (\% maximal acetylcholine response $=30.4 \pm 7.4 \%$ ). Both receptors were inhibited by $500 \mu \mathrm{M}$ levamisole (Ace-ACR-16 $=65.1 \pm 14.3 \%$ inhibition, Nam-ACR$16=79.5 \pm 7.7 \%$ inhibition), and responded to pyrantel, but only Ace-ACR-16 responded to oxantel. We used in silico homology modeling to investigate potential structural differences that account for the differences in agonist binding and identified a loop E isoleucine 130 of Nam-ACR-16 as possibly playing a role in oxantel insensitivity. These data indicate that key functional differences exist among ACR-16 receptors from closely related species and suggest mechanisms for differential drug sensitivity.

Keywords: hookworms, ion channels, electrophysiology, oxantel, homology modeling, anthelmintic sensitivity, acetylcholine receptors

\section{INTRODUCTION}

Hookworm infection by parasites of the family Ancylostomidae is a source of significant morbidity in humans and companion animals, with several species capable of invading the skin of human hosts and causing an inflammatory dermal syndrome known as cutaneous larva migrans (Hochedez and Caumes, 2007). However, the vast majority of patent human infection is caused by Necator 
americanus and Ancylostoma duodenale, with a lesser contribution from the zoonotic parasite of dogs and cats, Ancylostoma ceylanicum (Hoagland and Schad, 1978; Traub, 2013). These parasites are associated with low mortality rates, but a notable longevity of infection in the intestine of their host, where they feed on blood. Untreated hookworm infections account for anemia and malnutrition responsible for large economic productivity losses (Hotez, 2008) and over 4 million social disability-adjusted life years (DALYs) lost (Bartsch et al., 2016). Furthermore, these organisms are well suited to moderate increases in temperature associated with global climate change, and represent a continuing challenge for reducing the prevalence and spread of neglected tropical diseases (Weaver et al., 2010; Okulewicz, 2017; Blum and Hotez, 2018). The severity of their social and economic impact is primarily limited through the use of anthelmintics, drugs that remove helminths from their hosts. However, there are incongruities in susceptibility to anthelmintics among the different species of hookworm. For instance, Ancylostoma spp. are highly sensitive to the macrocyclic lactone, ivermectin, while $N$. americanus is incompletely cleared by doses up to $25 \mathrm{mg} / \mathrm{kg}$ (Behnke et al., 1993; Tritten et al., 2012). The extent to which differences in the targets of drugs across hookworm species govern anthelmintic efficacy has not been fully investigated. This is especially important for drugs that target other soil-transmitted helminths but cannot be used against hookworm, as is the case for the cholinergic acting oxantel used to treat Trichuris spp. (Keiser et al., 2013). To better understand the basis of differential species responses to anthelmintics and their role in physiology, one must first fully characterize the drug targets.

Some of the most important classes of anthelmintic targets are the ionotropic acetylcholine receptors (AChRs). Nematode acetylcholine-gated cation channels are responsible for fast, excitatory neurotransmission required for a range of essential physiological functions, including movement (Touroutine et al., 2005), feeding (McKay et al., 2004), and egg laying (Duerr et al., 2001) via regulation of muscle contractions. These nematode AChRs are orthologous but pharmacologically distinct from their vertebrate host counterparts, aiding specificity for drug targeting (Atchison et al., 1992) which induces paralysis and death or expulsion from the host. Nematode AChRs include 4 subtypes, BL- M- and N-AChRs, characterized by their subunit composition and preferential sensitivity to bephenium, levamisole, morantel and nicotine, respectively (Martin et al., 2005; Courtot et al., 2015). The major N-type AChR subunit is encoded by acr16 , which forms functional homopentameric receptors in the presence of the accessory protein RIC-3 (Bennett et al., 2012), and has been characterized from C. elegans (Ballivet et al., 1996; Raymond et al., 2000), Ascaris suum (Abongwa et al., 2016), Parascaris equorum (Charvet et al., 2018) and the dog hookworm Ancylostoma caninum (Choudhary et al., 2019). In C. elegans these receptors are expressed in body wall muscles and, along with the L-AChR, contribute to the acetylcholine response (Touroutine et al., 2005). In comparison, the acr-16 transcript from $A$. suum has been detected in numerous tissues including the pharynx, intestine, reproductive tract as well as body wall muscles (Abongwa et al., 2016).
ACR-16 is ideal for the study of ion channel drug targets because of the growing body of function data from multiple parasitic species, the ease of expression in Xenopus oocytes with only a single accessory protein, and the presence of a single subunit interface type (the site of agonist binding) since it is a homopentamer. In contrast, L-AChRs exist as heteropentamers composed of 5 different subunits in C. elegans that are each required for expression, but different subunits combinations exist in different parasitic nematode species (Williamson et al., 2009; Neveu et al., 2010; Boulin et al., 2011; Buxton et al., 2014). This means it is not possible to be certain which subunitsubunit interfaces exist, and each combination likely has distinct binding sites. These receptors also require multiple accessory proteins for functional expression (Boulin et al., 2008, 2011; Duguet et al., 2016).

The function of ACR-16 has not been reported in hookworms that infect humans, in which recent failure of the standard treatment of the benzimidazoles albendazole or mebendazole has been documented (Humphries et al., 2011; Soukhathammavong et al., 2012), and few alternative drugs are approved for treatment. Recent work has also identified an alarming increase in treatment failure of canine hookworm infections in the United States (Castro et al., 2019). The WHO put forth a goal of reducing morbidity of helminthiases by treating $75 \%$ of human childhood hookworm infections by 2030, extended from the original 2010 and 2020 deadlines (World Health Organization, 2012, 2020). However, this goal relies solely on the use of mebendazole or albendazole, and their increasingly intensive use raises the threat of the selection and spread of drug-resistant hookworm populations. Also approved for this indication, but little used in mass drug administration campaigns for hookworm control, are pyrantel pamoate and levamisole, albeit with more limited success (Botero and Castano, 1973; Krepel et al., 1993; Reynoldson et al., 1997; Keiser and Utzinger, 2008). Oxantel pamoate is effective against whipworm infections (Howes, 1972; Garcia, 1976; Barda et al., 2018), but lacks efficacy against hookworms (Keiser et al., 2013; Speich et al., 2014; Moser et al., 2016). A combination therapy of pyrantel and oxantel has been effective in treating soil-transmitted helminth infection (Rim et al., 1975; Grandemange et al., 2007), but high level of pyrantel resistance in A. caninum (Kopp et al., 2007) is indicative of the threat of drug resistance.

These limitations, coupled with the fact that the global prevalence of hookworm infection has only dropped by 9\% since 1996 (Hotez, 2018) despite large scale deworming programs, illustrates the urgent need to identify new safe and effective treatments to minimize the risk of rising hookworm infection prevalence. By characterizing understudied nematode ion channels, we may better understand the mechanisms by which current anthelmintics work and discover new targets to aid in the discovery of novel anthelmintics.

Here we report the identification and cloning of acr-16 from A. ceylanicum and $N$. americanus, which encode functional $\mathrm{N}$-type AChRs, the first ion channels to be so characterized from hookworm species that infect humans. Despite high sequence similarity between these hookworm acr-16, and with previously characterized nematode acr-16, our results identify 
key differences in their pharmacological profiles and suggest a structural rationale for the failure of oxantel to clear hookworm infections. These results emphasize the potential importance of species-specific drug discovery programs for hookworm infection, and perhaps for all parasitic nematodes.

\section{MATERIALS AND METHODS}

\section{cDNA Synthesis}

Adult A. ceylanicum cDNA was generously provided by Dr. John Hawdon (George Washington University School of Medicine \& Health Sciences, Washington, DC, United States). Adult A. ceylanicum and $N$. americanus were provided by the Dr. Raffi Aroian lab (University of Massachusetts Medical School, Worchester, MA, United States). Total RNA was isolated from 20 to 30 adult worms. Briefly, worms were thoroughly rinsed after removal from hamster hosts, snap frozen and crushed with a mortar and pestle until ground into a fine powder, which was suspended in TRIzol. RNA was isolated using Phenol TRIzol purification reagents and column purified with a Qiagen RNeasy MiniElute Cleanup Kit (Qiagen, Toronto, ON, United States). Quality of RNA was validated by visual inspection following electrophoresis though a denaturing agarose gel.

First strand cDNA was synthesized using a Maxima $\mathrm{H}$ Minus First Strand cDNA Synthesis Kit and treated with a double stranded DNase to remove genomic DNA (Thermo Fisher Scientific, Waltham, MA, United States).

\section{Cloning of Ancylostoma ceylanicum ACR-16}

The full-length sequence of $A$. ceylanicum ACR-16, was predicted from a BLASTP search of Haemonchus contortus and Caenorhabditis elegans ACR-16 against the genome of A. ceylanicum (BioProject IDs PRJNA231479, PRJNA72583) using the web-based platform WormBase ParaSite (Howe et al., 2017). Nested PCR was performed with inner primers designed to amplify a full length, gene-specific Ace-ACR-16 transcript flanked by $5^{\prime}$ NotI and $3^{\prime}$ ApaI restriction sites added to the ends of the primers (forward outer primer $5^{\prime}$ GATGGAAAAGTGCACTGGGTG-3', reverse outer primer 5'-GAGAGGAATAAGAAGAACAGACGAC-3', inner forward primer 5'-GCGGCCGCATGTGATGCGTTCGCTGGTC-3', inner reverse primer $5^{\prime}$-GGGCCCCACAAGGGTTAGGCGA CGAG-3').

\section{Cloning of Necator americanus ACR-16}

A partial sequence of $N$. americanus ACR-16, NECAME_12789, was obtained by BLASTP search. A primer specific for the common nematode $5^{\prime}$ trans-splice leader 1 (SL1) was used to amplify the $5^{\prime}$ end and a poly-A primer was used to amplify the $3^{\prime}$ end of Nam-acr-16. Cloned amplicons were verified Sanger sequencing (at Genome Quebec). Full length sequences were obtained from nested PCR with an inner primer flanked by $5^{\prime}$ NotI and $3^{\prime}$ ApaI restriction sites added to the ends of the primers (SL1 outer forward primer, inner forward primer $5^{\prime}$ ATATAGCGGCCGCATGCGTTCGTTGGTCGTCT-3'， reverse outer primer 5'-CCTCAAAAATGTCTAGAGAGTTCG-3', inner reverse primer $5^{\prime}$-GGGCCCAGAGTTCGATCTAGGCG ACA-3').

\section{Sequence Analysis}

Signal peptide prediction was performed using the webbased program SignalP 5.0 (Nielsen and Krogh, 1998) and by sequence alignment homology using Geneious 7.17 (https://www.geneious.com). Geneious was used for all primer design [Primer3 plugin (Rozen and Skaletsky, 2000)], transmembrane domain predictions, sequence alignment and analysis (Kearse et al., 2012). Primers were synthesized by Thermo Fisher Scientific.

\section{cRNA Synthesis and Xenopus laevis Oocyte Expression}

PCR products were subcloned into the pGEMT- Easy vector (Invitrogen, Waltham, MA, United States), grown using standard molecular biology techniques and plasmids were sequenced by Genome Quebec. Ace- and Nam-acr-16 were cloned into the Xenopus laevis oocyte expression vector pTD2 (Duguet et al., 2016), a gift from Dr. T Duguet derived from pTB20 (Boulin et al., 2008). pTD2 contains a T7 promoter and the Xenopus $5^{\prime}$ and $3^{\prime}$ UTR of $\beta$-globin designed to improve stability of exogenous genes in the oocyte. pTD2 was linearized using NheI and in vitro transcription of capped copy RNA (cRNA) performed using a mMessage mMachine T7 Transcription kit according to the manufacturer's instructions (Ambion, Burlington, ON, United States). Freshly synthesized cRNA was DNase treated, precipitated using lithium chloride and stored in nuclease- free water at $-80^{\circ} \mathrm{C}$.

All experiments using $X$. laevis complied with McGill University and Canadian Council on Animal Care animal protocols. Adult female X. laevis were purchased from Xenopus 1 (Dexter, Michigan). All surgical procedures and animal care were performed by trained personnel as outlined in AUP 20157758 issued by the McGill Animal Care Committee. Ovaries of $X$. laevis were surgically extracted from adult female frogs under 0.15\% MS-222 tricaine methanesulphonate anesthesia (SigmaAldrich, Oakville, ON, United States), pH 7 corrected with sodium bicarbonate. Ovaries were cut into clumps containing roughly 15 oocytes and treated with collagenase type Ia from Clostridium (Sigma-Aldrich, Oakville, ON, United States) in $\mathrm{Ca}^{2+}$-free oocyte ringer solution $(82 \mathrm{mM} \mathrm{NaCl}, 2 \mathrm{mM}$ $\mathrm{KCl}, 1 \mathrm{mM} \mathrm{MgCl}_{2}, 5 \mathrm{mM}$ HEPES buffer, $\mathrm{NaHCO}_{3}$ to $\mathrm{pH}$ 7.3) to defolliculate and isolate individual oocytes. Posttreatment, oocytes were allowed to recover at $19^{\circ} \mathrm{C}$ for $1-$ $2 \mathrm{~h}$ in the normal oocyte saline solution ND96 (96 mM $\mathrm{NaCl}, 2 \mathrm{mM} \mathrm{KCl}, 1 \mathrm{mM} \mathrm{MgCl} 2,1 \mathrm{mM} \mathrm{CaCl}_{2}, 5 \mathrm{mM}$ HEPES buffer) supplemented with pyruvate $(2.5 \mathrm{mM})$ as a carbon source and penicillin $(100 \mathrm{U} / \mathrm{ml})$ and streptomycin $(100 \mu \mathrm{g} / \mathrm{ml})$.

\section{Oocyte Injections}

25-50 ng of either Ace-acr-16 or Nam-acr-16 cRNA alone, or in equal amounts with cRNA encoding the accessory 
protein Hco-RIC-3 (accession \# HQ116823), were loaded into mineral oil-filled borosilicate glass pipettes pulled from a P1000 Flaming/Brown micropipette puller (Sutter Instrument Co, Novato, CA, United States) and injected into the cytoplasm of the vegetal pole of stage V or VI oocytes using a Nanoject II (Drummond Scientific Company, Broomall, PA, United States). Water injected oocytes acted as a negative control.

Oocytes were allowed a minimum of $24 \mathrm{~h}$ to synthesize and express receptors, then assayed daily afterward. ACR16 is a cation channel that gates $\mathrm{Na}^{+}$and $\mathrm{Ca}^{2+}$ ions, which can in turn activate intracellular $\mathrm{Ca}^{2+}$-gated $\mathrm{Cl}^{-}$ channels endogenous to $X$. laevis oocytes. To counteract the activity of these endogenous chloride channels, selected oocytes were incubated with $100 \mu \mathrm{M}$ of the $\mathrm{Ca}^{2+}$ chelator BAPTA-AM (Sigma-Aldrich, Oakville, ON, United States), for $1 \mathrm{~h}$, then washed in ND96 immediately prior to experiments.

\section{Drug Solutions}

Unless otherwise stated, each compound was purchased from Sigma-Aldrich and dissolved in ND96 stock concentrations. Where noted, compounds were dissolved in pure DMSO and diluted in ND96 to a final concentration containing $<0.1 \%$ DMSO: acetylcholine chloride, choline, betaine, (-)-nicotine hydrogen tartrate, glucosamine $\mathrm{HCl}$, sodium gluconate, bephenium hydroxynaphthoate (DMSO), nornicotine, mecamylamine hydrochloride (DMSO), levamisole - (-)tetramisole hydrochloride, pyrantel citrate (DMSO), oxantel pamoate (DMSO), morantel citrate (DMSO), ivermectin (DMSO), BAPTA-AM (DMSO).

\section{Electrophysiology}

Two-electrode voltage clamp (TEVC) electrophysiology was used to measure the function of expressed ion channels. Briefly, oocytes were placed in a $212.5 \mu \mathrm{l}(85 \mu \mathrm{l} / \mathrm{mm}, 2.5 \mathrm{~mm}$ tall $)$ RC-1Z perfusion chamber (Harvard Apparatus, Saint-Laurent, QC, United States) and pierced by one voltage clamping, and one current passing electrode. Glass microelectrodes (1$5 \mathrm{M} \Omega$ ) backfilled with $3 \mathrm{M} \mathrm{KCl}$ were connected to headstages (Axon Instruments, Foster City, CA, United States) by Ag| $\mathrm{AgCl}$ wires feeding into a GeneClamp 500B operational amplifier (Axon Instruments), with which user-defined holding potentials allows the measurement of changes in current across the oocyte membrane. Except for current-voltage studies, all oocytes were clamped at a holding potential of -60 $\mathrm{mV}$. For current-voltage studies oocytes were subject to repeated exposures of $100 \mu \mathrm{M}$ acetylcholine at holding potentials ranging from $-75 \mathrm{mV}$ to $+50 \mathrm{mV}$, increasing by increments of $25 \mathrm{mV}$.

ND96 (0.1\% DMSO) and the drugs used in this study were gravity-perfused into the oocyte chamber with a solution exchange rate of less than $500 \mathrm{~ms}$. Once a maximal current was achieved, drug application ceased, and saline solution was restored. All agonist responses were normalized to a maximal acetylcholine response by exposing individual replicate oocytes to acetylcholine before agonist exposure. To test antagonism, compounds at indicated concentrations were co-applied to oocytes with an $\mathrm{EC}_{50}$ concentration of acetylcholine. For current-voltage studies a final $100 \mu \mathrm{M}$ acetylcholine was prepared in the following solutions: ND96, $96 \mathrm{mM}$ sodium gluconate, $96 \mathrm{mM}$ glucosamine $\mathrm{HCl}$, $1.8 \mathrm{mM} \mathrm{CaCl}_{2}$.

Recordings were digitized using Digidata 1322A (Axon Instruments). Only oocytes with intact membranes capable of maintaining voltage clamp were used.

\section{In silico Homology Modeling}

Modeller v9.23 was used to generate a homology model of the extracellular domain (ECD) of ACR-16 from A. ceylanicum and N. americanus, C. elegans, and Trichuris muris (Šali and Blundell, 1993). The crystallized chimeric human a-7 extracellular domain/Lymnaea stagnalis acetylcholine binding protein bound to epibatidine in an open conformation (protein data bank 3SQ6) served as a template for homology modeling ( $\mathrm{Li}$ et al., 2011). Fifty homodimer models were generated for each species of ACR-16, including the creation of models for each amino acid substitution, to recreate the binding domain between adjacent subunits, and the best models were chosen for docking simulations based on Molpdf scores and Ramachandran plot analysis calculated by Modeller.

Homodimers were used to prepare in silico ligand binding analysis of a single binding site between adjacent subunits, implemented by AutoDock Vina (Trott and Olson, 2010). Molecules were instructed to bind within volume of a $15 \times 15 \times 15 \AA$ box encompassing the orthosteric binding site.

Fifty binding orientations were generated per root mean square from best fit with a default exhaustiveness value of 8 and the best binding poses were chosen according to predicted binding energies. All imaging was performed using USCF Chimera (Pettersen et al., 2004).

\section{Statistical Analysis}

All statistical analyses were performed using Prism 6.0 (GraphPad Software, San Diego, CA, United States). Semilog concentration-response curves were generated using a non-linear regression defined as:

$$
\operatorname{Imax}=\frac{1}{\left[1+\left(\frac{E C 50}{[D]^{\mathrm{h}}}\right)\right]}
$$

where Imax is the maximal current response, [D] is the concentration of drug, $\mathrm{EC}_{50}$ is the value of $[\mathrm{D}]$ at $50 \%$ maximal response, and $\mathrm{h}$ is the Hill slope which was used to gauge positive cooperativity for agonist binding. No sample calculation was performed in this study.

\section{Ethics Statement}

All experiments complied with McGill University and Canadian Council on Animal Care animal protocols. All surgical procedures and animal care were performed by trained personnel as outlined in AUP 2015-7758 issued by the McGill Animal Care Committee. 


\section{RESULTS}

\section{Cloning}

Nested PCR of Ace- (accession \# MT163735) and Nam-acr-16 (accession \# MT163736) each generated transcripts encoding 498 amino acid polypeptides. The sequence alignment (Figure 1) illustrates that both subunits contain signature pentameric ligand-gated ion channel (pLGIC) cation characteristics including a motif for cation selectivity, presence of a predicted cys-loop, 4 transmembrane domain regions, and a predicted signal peptide cleavage site after residue 21 .

The amino acid sequences of Nam- and Ace-ACR-16 share 75$78 \%$ identity with ACR- 16 from the clade III nematodes A. suum and $P$. equorum, as well as the clade $\mathrm{V}$ free-living nematode C. elegans (Meldal et al., 2007). The greatest degree of shared identity was among the hookworm ACR-16 receptors (95-98\%) and the closely related Hco-ACR-16 (84-88\%). Ace- and NamACR-16 differ in amino acids at 22 residues, primarily within the putative signal peptide and in the C-terminal region. The A. ceylanicum and A. caninum receptors differ in 8 residues, half of which are located in the signal peptide. Regions of highest similarity include the transmembrane domains and the large extracellular domain; however, some differences exist in the aromatic loop regions that comprise the orthosteric ligand binding domain and could play a role in differential ligand specificity.

The human hookworm ACR-16 receptors expressed relatively quickly, producing currents on a timescale and magnitude similar to those reported for other ACR-16s (Raymond et al., 2000; Abongwa et al., 2016; Charvet et al., 2018; Choudhary et al., 2019). Maximal responses were detected $48 \mathrm{hr}$ post-cRNA injection and currents were detectable until oocyte quality degraded to the point of loss of membrane integrity, roughly 4-5 days after injection. Oocytes expressing Ace-ACR-16 alone elicited very small, but detectable current responses upon an initial $1 \mathrm{mM}$ acetylcholine application, used to screen for functional expression (Figure 2A).

Oocytes co-injected with Ace-acr-16 and H. contortus ric3 elicited large concentration-dependent currents in response to acetylcholine as early as $24 \mathrm{~h}$ after injection (Figure 2B), while oocytes injected with water produced no response. In comparison, formation of detectable Nam-ACR-16 responses required the presence of RIC-3 (Figure 2A), but with some notable and surprising differences. Nam-ACR-16 required $48 \mathrm{~h}$ for functional expression, the magnitude of the acetylcholine response was significantly smaller than for Ace-ACR-16, and the signal from repeated exposures to acetylcholine diminished over time (Figure 2C), in contrast to responses in Ace-ACR-16 injected oocytes, which remained constant (Figure 2D). These differences were consistent regardless of the amount of Nam-acr16 cRNA injected.

\section{Time Between Agonist Exposures}

To investigate the reduction in Nam-ACR-16 signal from repeated exposures to a single concentration of acetylcholine, we measured the change in current amplitude as a function of time between exposures to $1 \mathrm{mM}$ acetylcholine (Figure 3). Oocytes were first allowed to recover from voltage clamp and equilibrate in ND96 buffer for 1 min before recording initial responses. Incubation time prior to first exposure to acetylcholine did not influence the magnitude of the initial response.

If agonist exposure generated a refractory desensitized state in Nam-ACR-16, lengthening the recovery time between exposures should reproduce maximal responses once a greater proportion of receptors was again primed for activation. Up to $1 \mathrm{~min}$ after an initial response to acetylcholine, subsequent applications generated attenuated responses, and a third application sometimes failed to generate a response. Only after 2 min continual washout with ND96 solution did we see rescue of maximal amplitude, indicating a very slow but completely reversible desensitization period.

\section{Pharmacology}

Beyond the differences reported above, we found that acetylcholine was more potent on Ace-ACR-16 $\left(\mathrm{EC}_{50}=20.64 \pm 0.32 \mu \mathrm{M}\right.$; Hill slope $\left.=1.55 \pm 0.13\right)$ than on NamACR-16 $\left(\mathrm{EC}_{50}=170.1 \pm 19.23 \mu \mathrm{M}\right.$; Hill slope $\left.=1.11 \pm 0.37\right)$ (Figure 4). The lower sensitivity of Nam-ACR-16 was magnified in response to nicotine, which acted as a weak partial agonist for this receptor $\left(\mathrm{EC}_{50}=597.9 \pm 59.12 \mu \mathrm{M}\right.$; Hill slope $=6.19 \pm 1.43$; maximal acetylcholine response $=30.4 \pm 7.4 \%$ ). Initial NamACR-16 nicotine trials produced such small currents that we originally suspected degradation of the drug. However, Ace-ACR-16 receptors expressed in the same week produced large and reproducible responses to nicotine, comparable to those elicited from acetylcholine $\left(\mathrm{EC}_{50}=24.37 \pm 2.89 \mu \mathrm{M}\right.$; Hill slope $=1.43 \pm 0.15)$ (Figure 4B).

\section{Current Voltage Trials}

ACR-16 receptors gate $\mathrm{Na}^{+}$and $\mathrm{Ca}^{2+}$ ions into the cell, which in turn can activate endogenous intracellular $\mathrm{Ca}^{2+}$-gated $\mathrm{Cl}^{-}$ channels in X. laevis oocytes (Miledi and Parker, 1984). To ensure that receptor activation measurements were not influenced by this cascading $\mathrm{Ca}^{2+}$ signaling, we incubated oocytes expressing Ace-ACR-16 with the intracellular $\mathrm{Ca}^{2+}$ ion chelator BAPTA-AM $(100 \mu \mathrm{M})$ for $1 \mathrm{~h}$. Following incubation, oocytes were washed in ND96 and voltage clamp measurements made immediately after. This receptor was chosen because the stability and reproducibility of tracings provided better accuracy than Nam-ACR-16 for comparing BAPTA-treated versus untreated oocytes. Figure 5A shows that BAPTA-AM treatment did not affect the sensitivity or activation profile of Ace-ACR-16. However, it did alter the reversal potential $[(+)$ BAPTA-AM $=13.55 \mathrm{mV}$; $(-)$ BAPTA$\mathrm{AM}=-8.53 \mathrm{mV}]$ and slope $[(+) \mathrm{BAPTA}-\mathrm{AM}=34.6 \pm 2.4 ;(-$ )BAPTA-AM $=67.7 \pm 2.6]$ of the current-voltage relationship, indicating an altered population of ions transported across the membrane (Figure 5B). Because of the variable pharmacology of ACR-16 receptors reported in the literature, we sought to validate the gating of $\mathrm{Na}^{+}$and $\mathrm{Ca}^{2+}$ ions by completely replacing the buffer ion composition with sodium gluconate $(96 \mathrm{mM})$ as an anion replacement, glucosamine $\mathrm{HCl}(96 \mathrm{mM})$ as a cation replacement or $\mathrm{CaCl}_{2}(1.8 \mathrm{mM})$. Reversal potential values from these ion replacement curves are in keeping with the values 


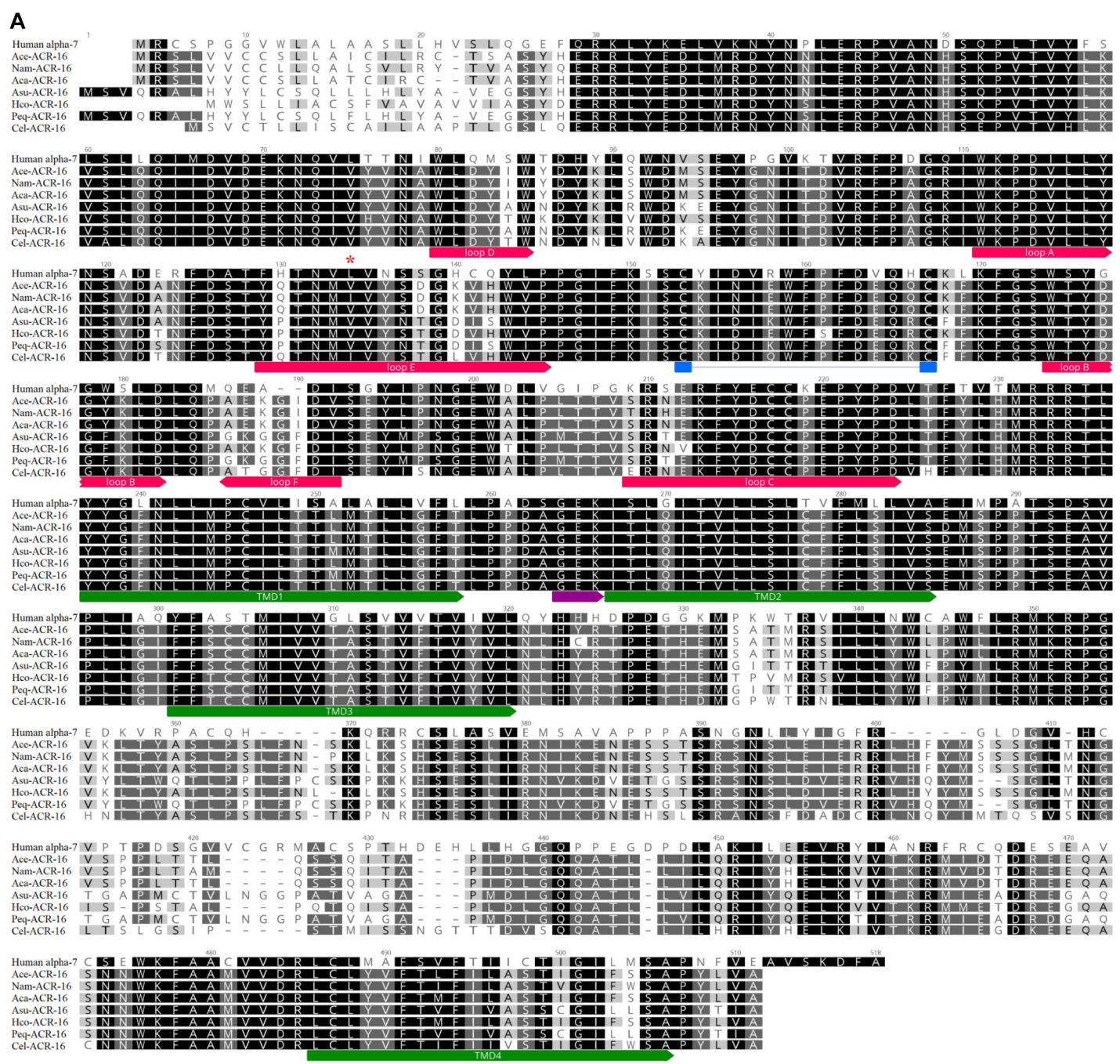

\begin{tabular}{|l|r|r|r|r|r|r|r|r|}
\hline B & \multicolumn{1}{|c|}{$\begin{array}{c}\text { Human } \\
\alpha-7\end{array}$} & $\begin{array}{c}\text { Ace- } \\
\text { ACR-16 }\end{array}$ & $\begin{array}{c}\text { Nam- } \\
\text { ACR-16 }\end{array}$ & $\begin{array}{c}\text { Aca- } \\
\text { ACR-16 }\end{array}$ & $\begin{array}{c}\text { Asu- } \\
\text { ACR-16 }\end{array}$ & $\begin{array}{c}\text { Hco- } \\
\text { ACR-16 }\end{array}$ & $\begin{array}{c}\text { Peq- } \\
\text { ACR-16 }\end{array}$ & $\begin{array}{c}\text { Cel- } \\
\text { ACR-16 }\end{array}$ \\
\hline Human $\boldsymbol{\alpha - 7}$ & & 44.4 & 43.8 & 44.0 & 43.5 & 43.7 & 43.5 & 44.2 \\
\hline Ace-ACR-16 & 44.4 & & 95.4 & 98.0 & 77.5 & 87.5 & 76.9 & 78.0 \\
\hline Nam-ACR-16 & 43.8 & 95.4 & & 96.0 & 75.7 & 86.3 & 75.0 & 77.8 \\
\hline Aca-ACR-16 & 44.0 & 98.0 & 96.0 & & 76.5 & 87.5 & 75.9 & 77.6 \\
\hline Asu-ACR-16 & 43.5 & 77.5 & 75.7 & 76.5 & & 78.4 & 99.2 & 73.4 \\
\hline Hco-ACR-16 & 43.7 & 87.5 & 86.3 & 87.5 & 78.4 & & 78.4 & 77.6 \\
\hline Peq-ACR-16 & 43.5 & 76.9 & 75.0 & 75.9 & 99.2 & 78.4 & & 73.0 \\
\hline Cel-ACR-16 & 44.2 & 78.0 & 77.8 & 77.6 & 73.4 & 77.6 & 73.0 & \\
\hline
\end{tabular}

FIGURE 1 | (A) Sequence alignment of ACR-16 from Ancylostoma ceylanicum (accession \# MT163735), Necator americanus (accession \# MT163736) Ancylostoma caninum (accession \# QEM53385.1), Caenorhabditis elegans (accession \# CCD64102.1), Haemonchus contortus (accession \# AZS27833.1), Ascaris suum (accession \# KP756901), Parascaris equorum (accession \# AZS27834.1), and the human a7 acetylcholine receptor subunit (accession \# P36544.5). Amino acids are shaded by consensus sequence similarity; black is most, and white is least similar. The ECD ligand binding loops A-E are denoted in red, the characteristics cys-loop is indicated in blue, the cation selectivity motif is shown in purple and the transmembrane domains are in green. Red star indicates site of lle130 of Nam-ACR-16 (B)\% Identity matrix of the polypeptide sequences for comparison. 
A

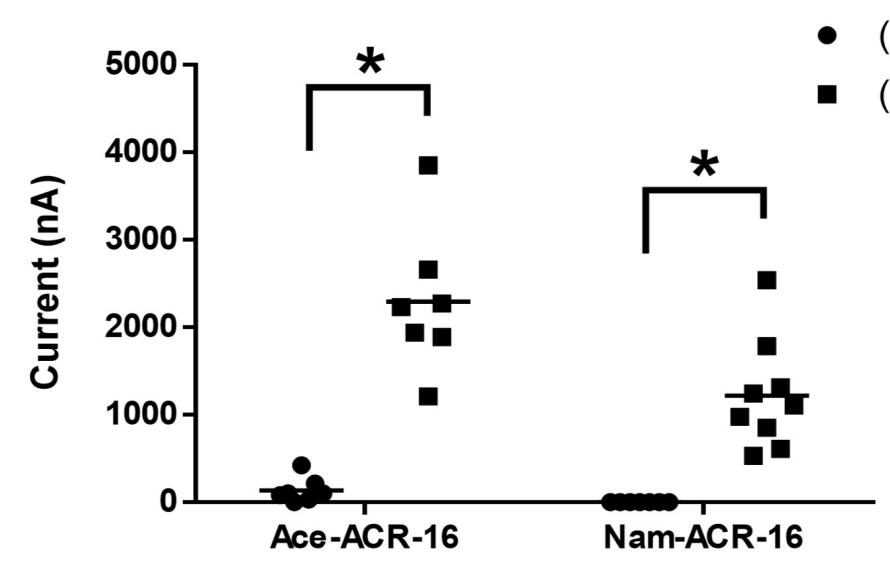

$(-)$ RIC-3

$(+)$ RIC-3

B

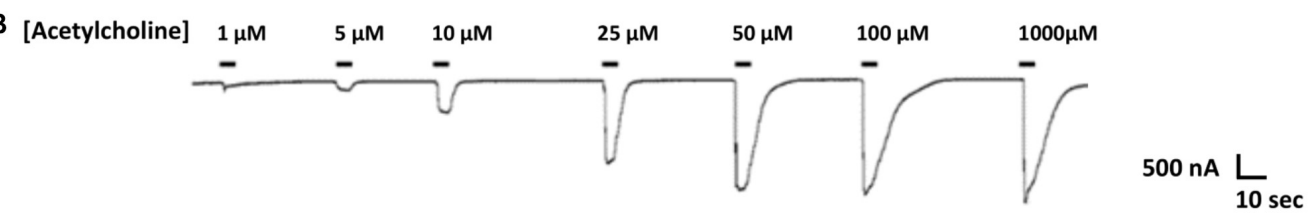

C [Acetylcholine] $1000 \mu \mathrm{M}$

$1000 \mu \mathrm{M}$

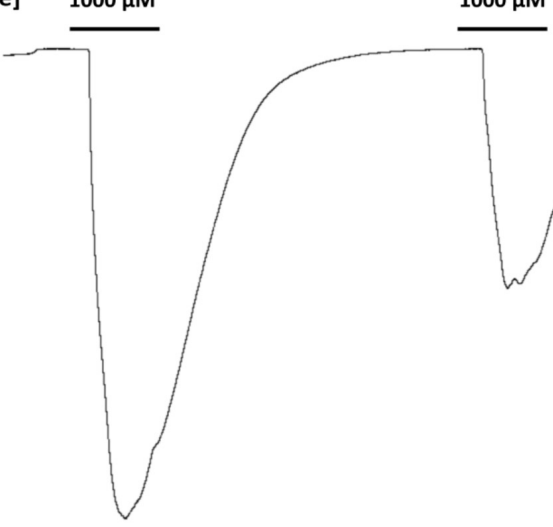

$1000 \mu \mathrm{M}$
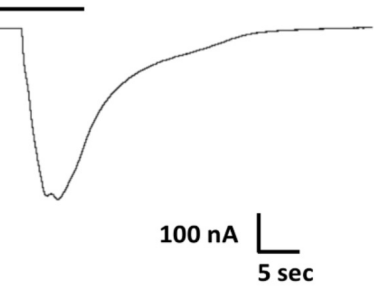

D [Acetylcholine]

$1000 \mu \mathrm{M}$

$1000 \mu \mathrm{M}$

$1000 \mu \mathrm{M}$
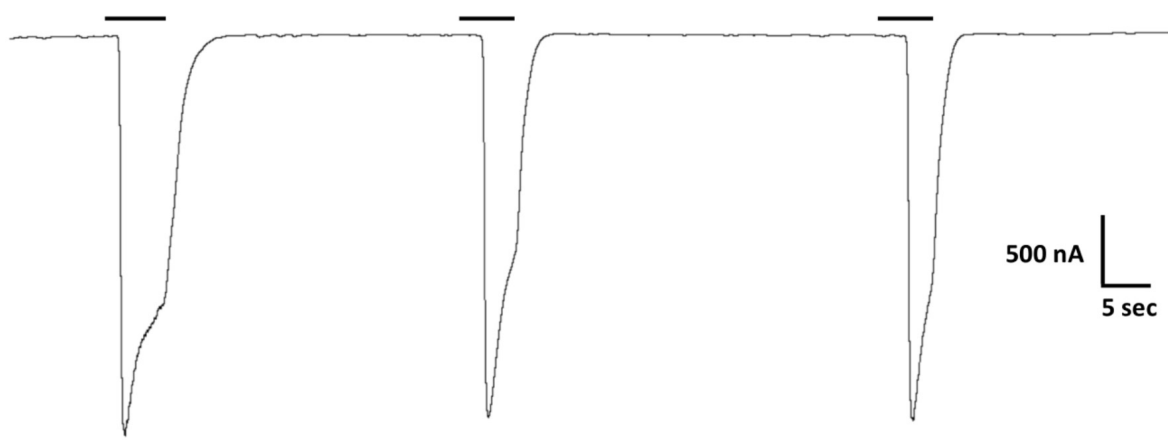

FIGURE 2 | Functional expression of ACR-16 receptors in response to acetylcholine. (A) Amplitude of current response to $1 \mathrm{mM}$ acetylcholine in the presence or absence of the accessory protein RIC-3 $48 \mathrm{~h}$ after injection. Each point represents recordings from individual oocytes. $n>7 ; p<0.05$. (B) Ace-ACR-16 response profile to increasing concentrations of acetylcholine. (C) Reproducibility of Nam-ACR-16 and (D) Ace-ACR-16 current response profile to repeated concentrations of acetylcholine. Nam-ACR-16 displays reduced current responses to repeated exposures to acetylcholine. 

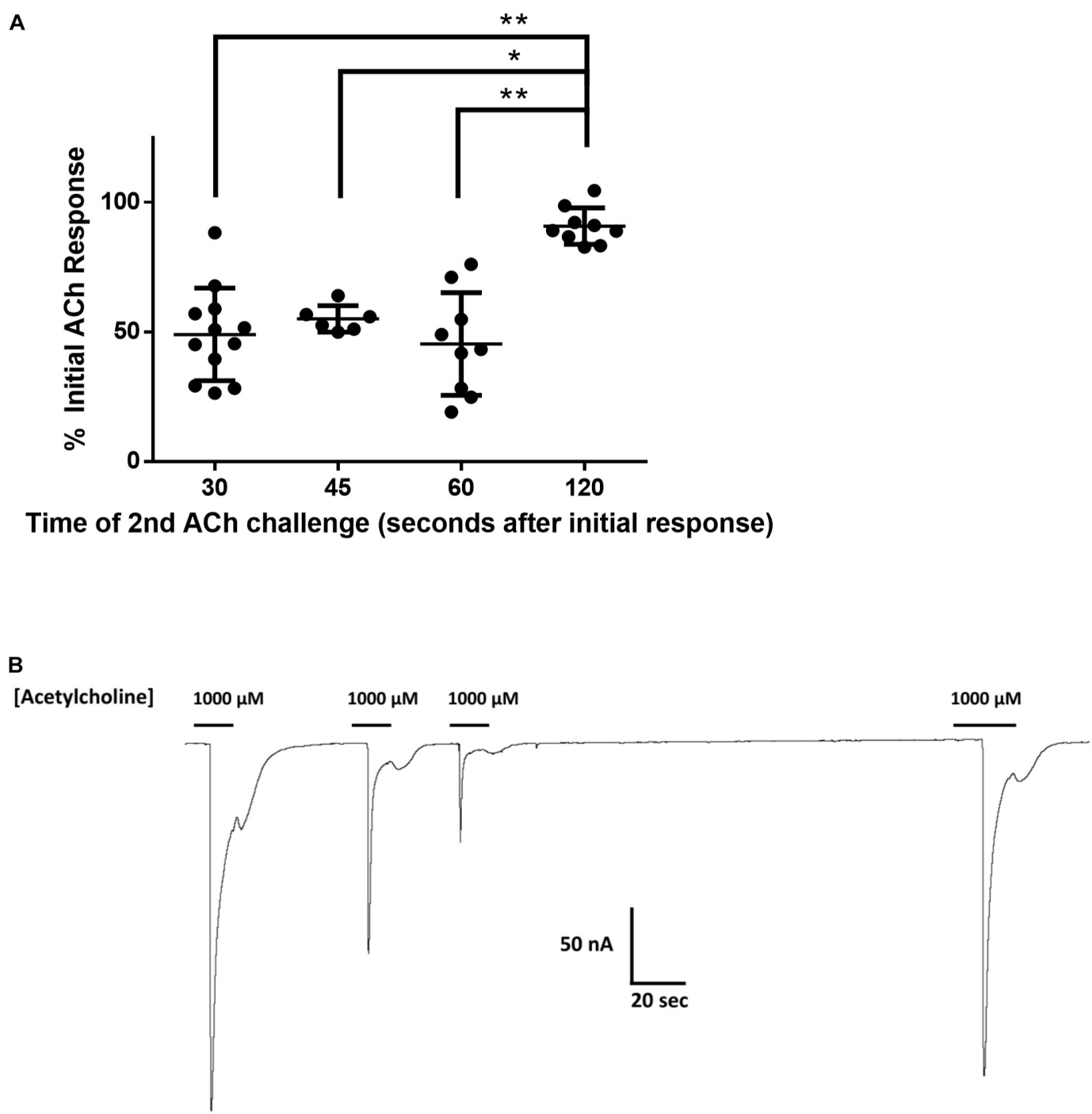

FIGURE 3 | (A) The effect of time between subsequent applications of $1 \mathrm{mM}$ acetylcholine on the magnitude of current elicited from Nam-ACR-16. Oocytes given 2 min recovery time from an initial acetylcholine exposure produced significantly larger currents than any other timepoint. Data at each time point were derived from experiments conducted on oocytes from at least two different frogs. $n>6,{ }^{*} p=0.0004,{ }^{\star *} p<0.0001$. (B) Representative tracing of current responses from oocytes expressing Nam-ACR-16 induced by varying time between exposures to acetylcholine.

indicative of a, primarily $\mathrm{Na}^{+}$, cation-gated AChR (Harrow and Gration, 1985). In the absence of $\mathrm{Na}^{+}$and $\mathrm{Ca}^{2+}$ ions in solution, no current was detectable when acetylcholine was applied (Figure 5C, glucosamine $\mathrm{HCl}$ ).

\section{Panel of Anthelmintics and Classic Cholinergics Against the ACR-16 Receptors}

Previous studies indicate that Ancylostoma spp. and $N$. americanus respond differently to anthelmintics (Behnke et al., 1993; Richards et al., 1995; Tritten et al., 2011). To investigate differences in anthelmintic sensitivity between these receptors, we tested them against a panel of drugs, including cholinergic anthelmintics.
Nematodes possess 4 subtypes of AChRs: nicotine $(\mathrm{N}$ type), levamisole (L-type), morantel (M-type) and bephenium sensitive (B-type). As expected for an N-type AChR, neither receptor was activated by levamisole or bephenium. Ace-ACR16 was only weakly activated by the tetrahydropyrimidines oxantel (15.6 $\pm 9.6 \%$ maximal acetylcholine response), pyrantel $(12.5 \pm 7.5 \%)$ and morantel $(5.5 \pm 3.9 \%)$, while Nam-ACR-16 was only activated by pyrantel $(8.3 \pm 6.0 \%)$ (Figure 6A). Raymond et al. (2000) showed that the C. elegans ACR-16 is antagonized by levamisole. To further characterize the hookworm ACR-16s, we assayed compounds and anthelmintics known to modulate the activity of pLGICs. Supporting the findings of Raymond et al. (2000), we observed significant inhibition of acetylcholine-induced channel activation by levamisole for Ace-ACR-16 (65.1 $\pm 14.3 \%$ inhibition) and 

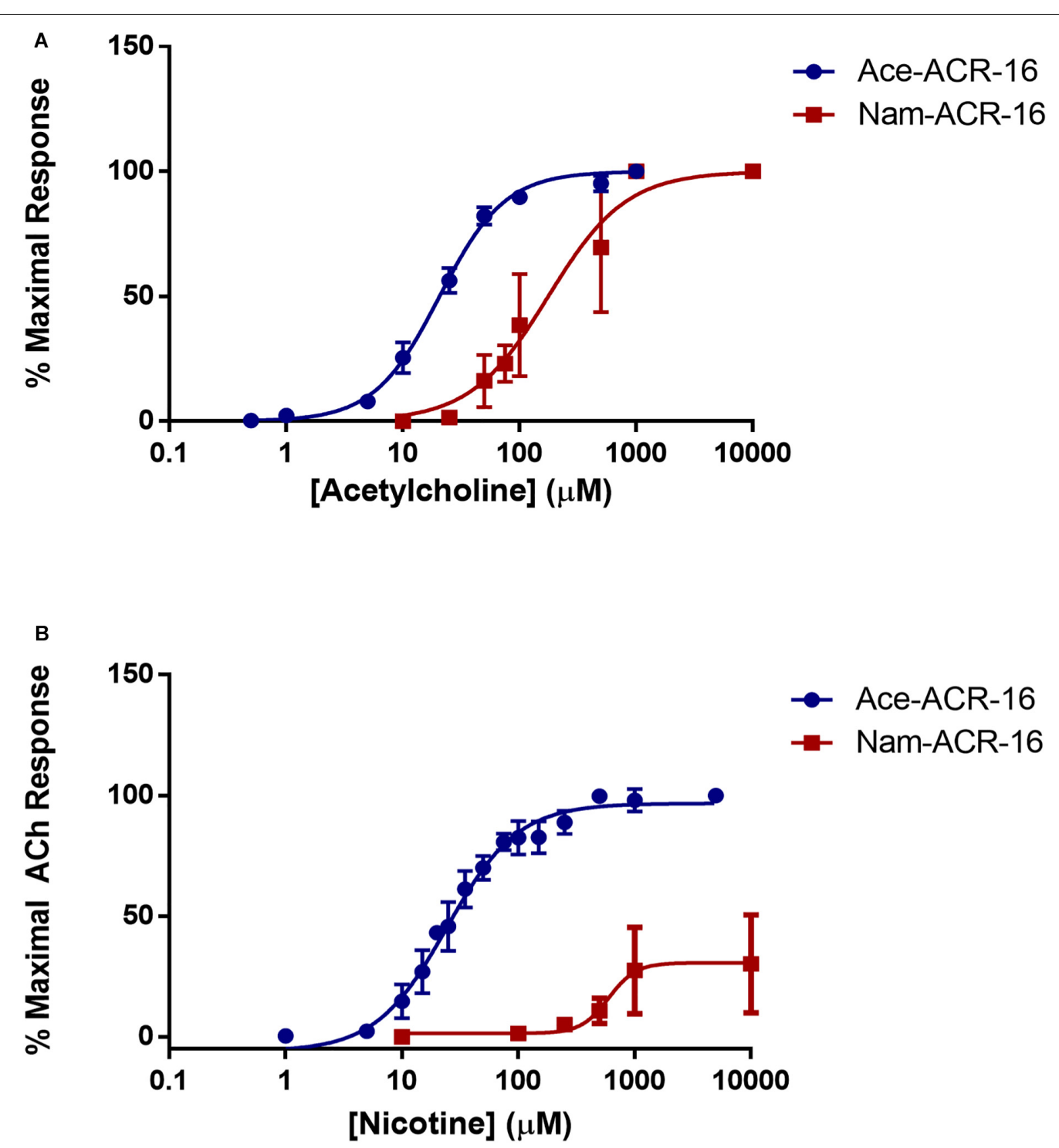

FIGURE 4 | (A) Concentration-response curves for acetylcholine on Ace- and Nam-ACR-16. Individual oocytes were exposed to increasing concentrations of acetylcholine and all responses were standardized to the maximal current achieved within each oocyte. $n>6$ (B) Concentration-response curves for nicotine on Ace- and Nam-ACR-16. Individual oocytes were exposed to repeated maximal concentrations of acetylcholine to determine stability of response, and to serve as a maximal effect reference to standardize all nicotine current responses to. Nicotine acts as a full agonist on Ace-ACR-16 but as a weak partial agonist of Nam-ACR-16 $n>6$.

Nam-ACR-16 (79.5 $\pm 7.7 \%)$ (Figure 6B). This inhibition appears to be irreversible and robust.

The classical non-competitive cholinergic antagonist mecamylamine was also inhibitory, with comparable inhibition of acetylcholine responses for Ace-ACR-16 (94.7 $\pm 4.7 \%$ inhibition) and Nam-ACR-16 (99.7 \pm 0.4\%) (Figure 6B). Ivermectin had no effect on acetylcholine-induced currents after either pre-treatment or simultaneous exposure of the oocyte.

\section{Homology Modeling}

We used homology modeling and in silico ligand docking predictions to investigate structural differences between the receptors that might underlie some of the differences in pharmacology (Figure 7). Acetylcholine and nicotine docked into the orthosteric binding pocket of both ACR-16 models with comparable predicted energies (Acetylcholine: Ace-ACR$16=-4.3 \mathrm{kcal} / \mathrm{mol}$, Nam-ACR-16 = $-4.0 \mathrm{kcal} / \mathrm{mol}$; nicotine: Ace-ACR-16 = -5.4 kcal $/ \mathrm{mol}$, Nam-ACR-16 = -4.6 kcal $/ \mathrm{mol})$. However, docking simulations simply place the ligand in a position forming bonds with the lowest predicted binding energies, and do not take into account hydrogen bonding and $\pi$-cation interactions required for activating pLGICs.

Both agonists oriented centrally into the binding pocket of Ace-ACR-16 with their cation nitrogens placed near aromatic residues of loops $B$ and $C$, notable for forming important $\pi$ cation bonds with ligands (Dougherty, 2008). In comparison, 


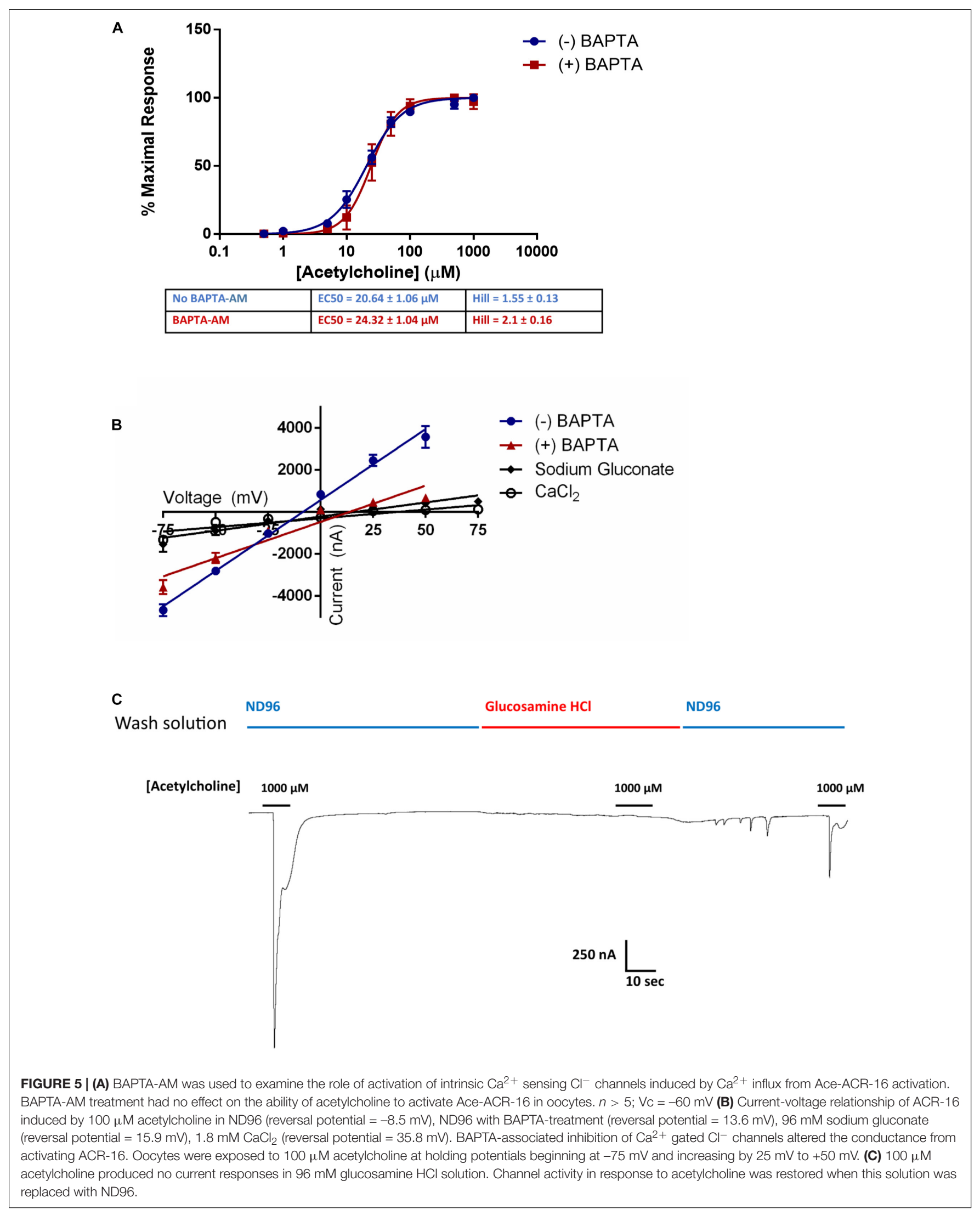




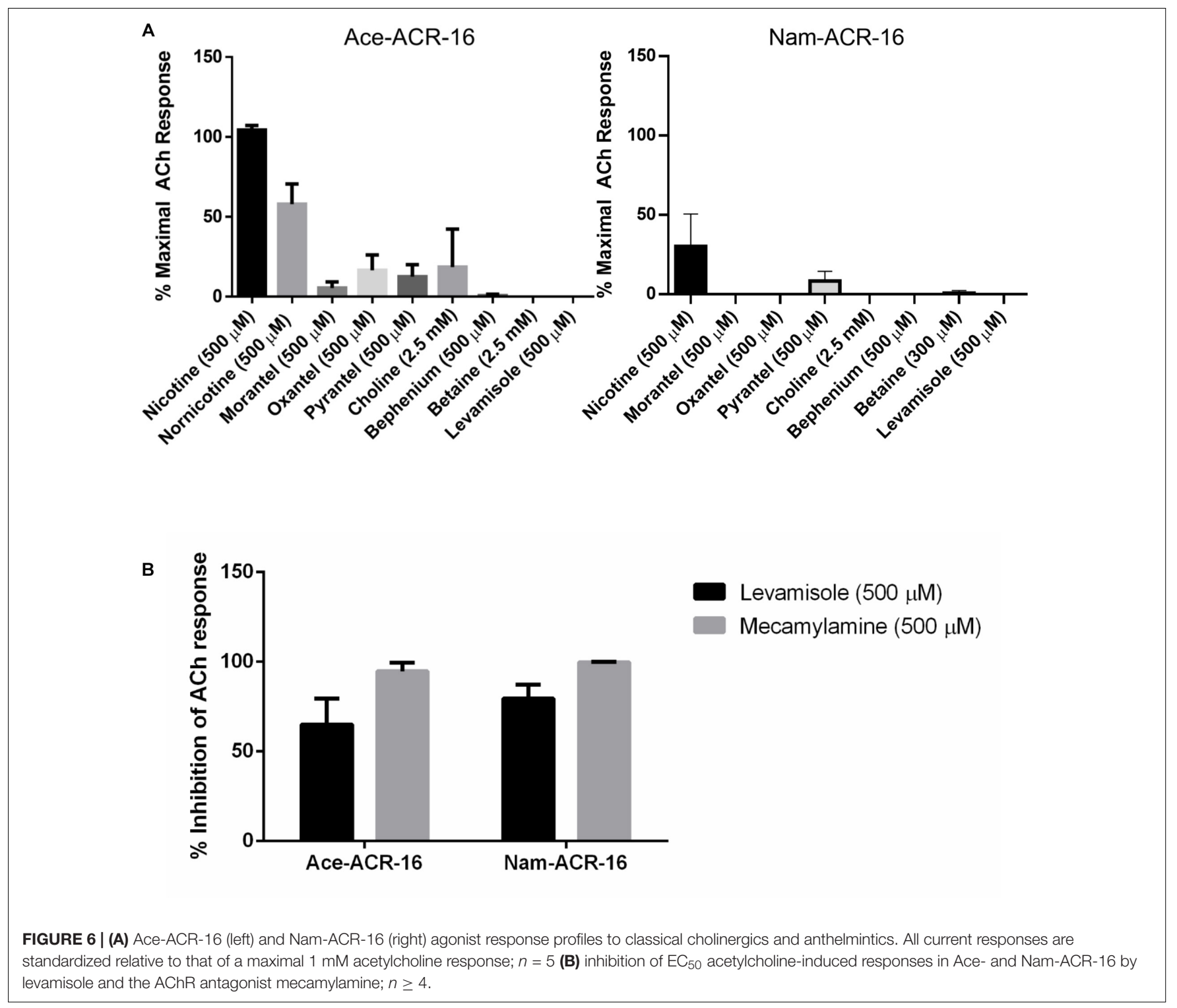

acetylcholine and nicotine docked more peripherally into NamACR-16, 4-5 $\AA$ closer to the transmembrane domain, placing their cation nitrogens further from the aromatic pocket than in Ace-ACR-16. These docking differences could offer a structural origin to for the lower affinity for the site of activation in Nam-ACR-16, potentially explaining the higher $\mathrm{EC}_{50}$ values for this receptor. Furthermore, in the Nam-ACR-16 model, nicotine molecules did not dock with the pyridine group presenting to Loop E residues of the complementary subunit, which are expected to hydrogen bond with a water molecule essential for agonist activation (Celie et al., 2004; Blum et al., 2010). Indeed, the best scoring docking simulation for Nam-ACR-16 flipped the nitrogenous ring of nicotine away from Loop D of the complementary subunit, roughly $9 \AA$ further than in the AceACR-16 docking model. This difference conceivable prevents the complete closure of binding pocket and could explain why nicotine acted as a partial agonist on Nam-ACR-16.
Interestingly, our model also predicted significant differences in tetrahydropyrimidine (oxantel, pyrantel, morantel) binding between these receptors. When constrained to bind in the Ace-ACR-16 orthosteric agonist binding pocket, oxantel $(-6.4 \mathrm{kcal} / \mathrm{mol})$, pyrantel $(-5.5 \mathrm{kcal} / \mathrm{mol})$ and morantel $(-5.7 \mathrm{kcal} / \mathrm{mol})$ all docked with similar energies, comparable to acetylcholine and nicotine. All compounds docked within loops A-C of the aromatic box and presented functional groups to the complementary subunit where they are expected to hydrogen bond with a water molecule within the pocket. Using the same constraints for the Nam-ACR-16 receptor, all three tetrahydropyrimidine docking simulations produced positive binding energies (oxantel $=+3.6 \mathrm{kcal} / \mathrm{mol}$; pyrantel $=+1.1 \mathrm{kcal} / \mathrm{mol}$; morantel $=+0.7 \mathrm{kcal} / \mathrm{mol}$ ) indicative of poor affinity. Only when binding parameters were extended to a large section of the extracellular domain was oxantel able to dock with a higher affinity, but still in a site and conformation 

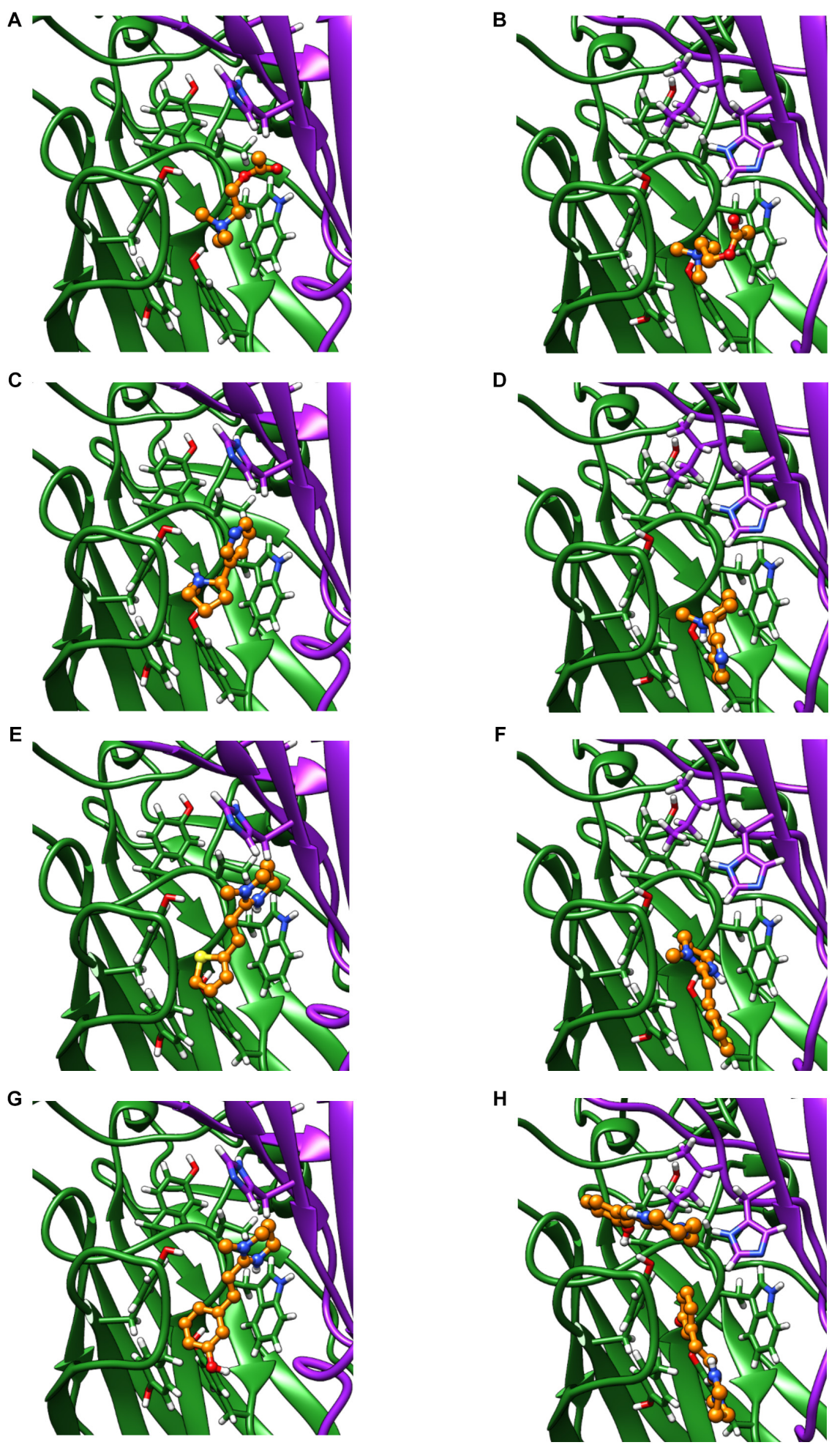

FIGURE 7 | Homology models of the Ace-ACR-16 and Nam-ACR-16, docking: acetylcholine (A,B), nicotine (C,D), pyrantel (E,F), and oxantel (G,H). The principal (+) subunit contributing to key residues of Loops A, B and C, is colored green and the subunit contributing the complementary (-) face of the binding pocket contributing Loops D, E and F is colored in purple ribbon. Carbon atoms of docked agonists are colored in orange ball and stick. Red and blue molecules show oxygen and nitrogen atoms, respectively. 


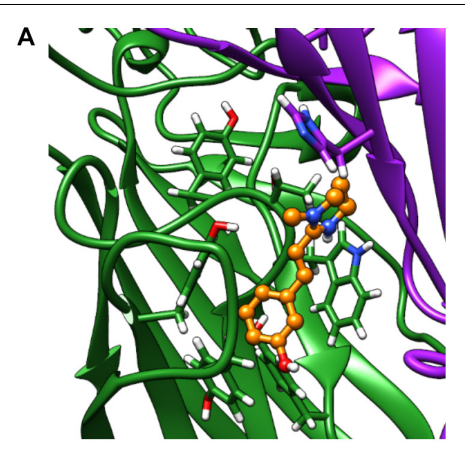

C

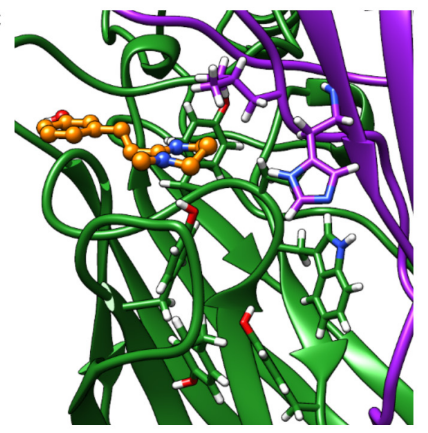

E

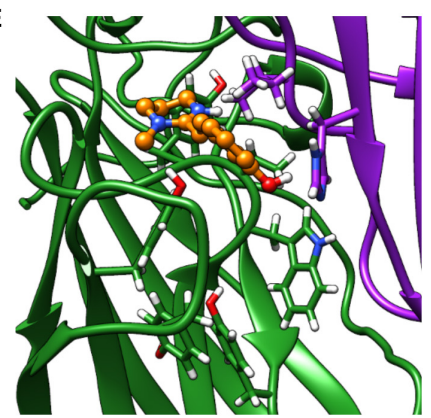

G

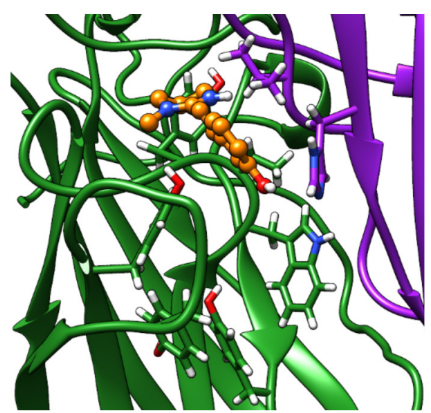

B

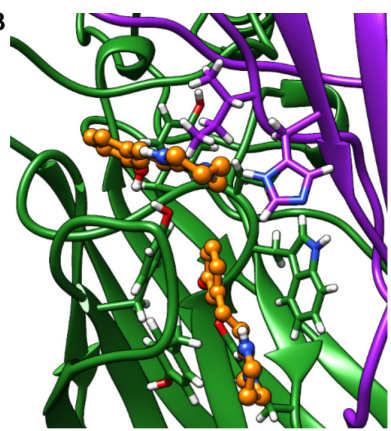

D

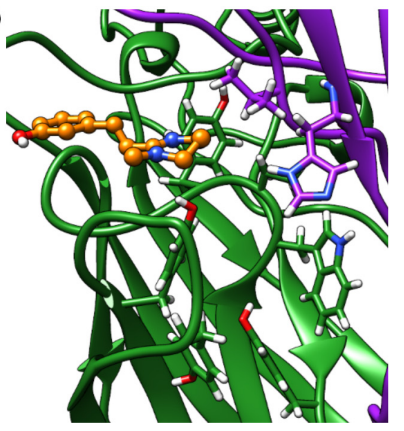

$\mathbf{F}$

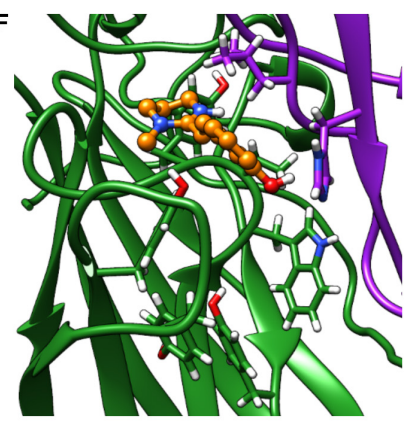

$\mathrm{H}$

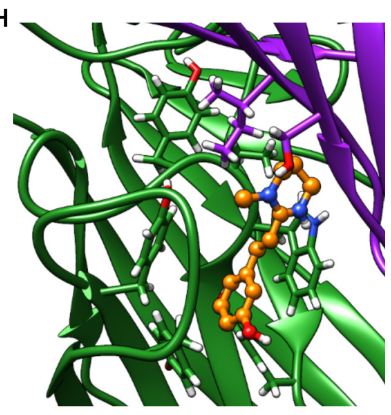

FIGURE 8 | Homology models of oxantel docking into: (A) Ace-ACR-16 V130I (B) Nam-ACR-16 (C) Nam-ACR-16 I130L (D) Nam-ACR-16 I130V (E) Cel-ACR-16 (F) Cel-ACR-16 I130L (G) Cel-ACR-16 I130V (H) Tmu-ACR-16.

peripheral to the main binding pocket. These poses either failed to present a functional group to the complementary subunit, or placed the compound above the aromatic box where they are not expected to form $\pi$-cation interactions.

Only the oxantel-insensitive Cel-ACR-16 and Nam-ACR16 possess an isoleucine on the complementary (-) subunit proximal to the binding pocket, compared to a leucine in the human $\alpha-7$ receptor, and a valine in all other published
ACR-16s. We modeled the Cel-ACR-16 receptor and also found an inability to dock oxantel $(+2.5 \mathrm{kcal} / \mathrm{mol})$, mirroring in vitro results (Raymond et al., 2000) (Figure 8). Interestingly, Ile130 in both Cel- and Nam-ACR-16 and the Val130 of the oxantelinsensitive Aca-ACR-16 points inward into the agonist binding site, whereas the side chain points in the opposite direction in Ace- and Asu-ACR-16, which both respond to oxantel. To determine if more negative space in this position is associated 
with improved docking predictions, we mutated the models of Nam- and Cel-ACR-16 from Ile130 to valine, which is one sidechain carbon shorter, or to a leucine, which has the same length as isoleucine but whose chain branches in the opposite direction. We then repeated the docking simulations for acetylcholine and oxantel (Figure 8) and found Val130 and Leu130 both allowed simulations to generate binding energies comparable to those of Ace-ACR-16 (Table 1), with oxantel better able to fit into the binding pocket. As expected, reverse mutation of the analogous position in Ace-ACR-16 (Val130 to isoleucine) had no effect on predicted binding parameters.

Oxantel does not clear hookworm infections in standard single-dose regimens, but is efficacious against the whipworm Trichuris spp. We mined the genome of Trichuris spp. and, using a curated gene annotation, obtained the predicted sequences of ACR-16 from T. muris, T. trichiura, and T. suis. All three species possess an analogous Ile130, and our homology modeling of T. muris indicates that this residue extends toward the binding pocket as in Cel- and Nam-ACR-16 (Figure 8). Remarkably, docking simulations of oxantel into Trichuris ACR-16 yielded strong predicted binding $(-5.4 \mathrm{kcal} / \mathrm{mol})$, and in orientations more central to the binding pocket, similar to poses in AceACR-16. However, the acr-16 sequence of Trichuris spp. are more divergent from the clade $\mathrm{V}$ nematodes and contains differences in the binding pocket. One of these differences is that the predicted Tmu-ACR-16 has an outward facing V129, whereas all the other ACR-16 models have a M129 intruding into the binding pocket, which may provide more space to accommodate oxantel. Future site-directed mutagenesis studies will be required to elucidate the functional effect of these changes.

Together with the electrophysiological data, our model predictions suggest that there are separate mechanisms of binding for nicotine and acetylcholine compared to tetrahydropyrimidines, and that the Nam-ACR-16 agonist binding pocket strongly discriminates between these two classes of molecules. A caveat to the interpretation of these homology modeling results is the observation of a pyrantel-induced signal in oocytes expressing Nam-ACR-16, but no signal in response to oxantel or morantel, a difference in efficacy inconsistent with predicted binding. It is possible that the smaller and decaying nature of Nam-ACR-16 responses to agonists, compared to

TABLE 1 | Calculated binding energies of in silico simulated agonist docking.

\begin{tabular}{lcc}
\hline & Binding energies $\mathbf{( k c a l / m o l})$ & \\
\hline Dimer & Acetylcholine & Oxantel \\
\hline Ace-ACR-16 V130 $\rightarrow$ I & -4.3 & -6.4 \\
Nam-ACR-16 & -4 & +4.3 \\
Nam-ACR-16 |130 $\rightarrow$ L & -4.4 & -3.3 \\
Nam-ACR-16 |130 $\rightarrow$ V & -4.7 & -4.4 \\
Cel-ACR-16 & -3.7 & +2.5 \\
Cel-ACR-16 |130 $\rightarrow$ L & -3.9 & -1.5 \\
Cel-ACR-16 I130 $\rightarrow \mathrm{V}$ & -4.2 & -2 \\
Tmu-ACR-16 & -4.9 & -5.4
\end{tabular}

Ace-ACR-16, could prevent detection of low proportions of activated receptors.

\section{DISCUSSION}

\section{Expression and Agonist Activity of Acetylcholine and Nicotine}

Much of our understanding of anthelmintic targets and their mechanisms of action is derived from studies of the free-living nematode, C. elegans (reviewed by Geary and Thompson, 2001), including the levamisole (Boulin et al., 2008) and ivermectin receptors (Cully and Paress, 1991). However, large differences in drug sensitivity have been reported between closely related parasitic nematodes, even those with high levels of sequence similarity in drug targets (Behnke et al., 1993; Tang et al., 2014; Schwarz et al., 2015). This suggests that model organisms are an appropriate starting point, but drug targets in each species of parasitic nematode must be studied individually to assess differences in pharmacodynamics. ACR-16 is one such drug target relevant for hookworms of humans and animals.

Our results indicate that the ACR-16 sequence is highly conserved across nematode species, especially the ligandbinding and transmembrane domains. With such high similarity, especially in the ligand-binding domain, one would predict very similar pharmacological profiles, and this generally holds true; Table 2 summarizes the current state of knowledge for ACR-16 receptors. As a general trend, a functional ACR-16 take 2-3 days to reach maximal expression, requires the RIC3 accessory protein, and responds to acetylcholine and nicotine at low $\mu \mathrm{M} \mathrm{EC}_{50}$ values. They are antagonized by the classic AChR antagonist mecamylamine and are not activated by levamisole or bephenium.

Despite these similarities, there are surprising differences that would not be predicted by phylogeny. The recently published $H$. contortus ACR-16 was not successfully functionally characterized, despite having high sequence identity with known functional ACR-16s (Charvet et al., 2018). An important caveat is that this protein (accession code \# AZS27833.1) differs from an earlier published sequence (accession code \# ABW07339.1) by a single amino acid in the cys-loop (serine versus proline in ABW07339.1). This proline residue has been reported to be of critical importance for ligand-activation in the pLGIC family (Lummis et al., 2005; Rienzo et al., 2016), and highlights the role that a single residue can play in receptor activation.

Another unexpected difference is that A. ceylanicum ACR16 responses were in the large microamp range, whereas the $N$. americanus ACR-16 receptor generated currents in the nanoamp to small microamp range. Yet, the amplitude of A. caninum ACR-16 responses reported by Choudhary et al. (2019) better match with those from $N$. americanus rather than A. ceylaniucm from its own genus. Furthermore, $N$. americanus ACR-16 failed to achieve maximal channel activation from nicotine (similar to Aca- and Cel-ACR-16, but dissimilar to Ace-, Peq- and Asu-ACR-16), and nicotine was $\sim$ fivefold less potent than acetylcholine, in contrast to the other published ACR-16s. 
TABLE 2 | Comparison of ACR-16 pharmacology.

\begin{tabular}{|c|c|c|c|c|c|}
\hline Species & $\begin{array}{l}\text { Acetylcholine } \\
\left.\text { response ( } \mu \mathrm{M} \mathrm{EC}_{50}\right)\end{array}$ & $\begin{array}{l}\text { Maximal response } \\
\text { (current) }\end{array}$ & $\begin{array}{l}\text { Nicotine response }(\mu \\
\left.\mathrm{M} \mathrm{EC}_{50}\right)\end{array}$ & $\begin{array}{l}\text { Response to } \\
\text { oxantel? }\end{array}$ & Research group \\
\hline A. ceylanicum & 20.64 & $n A-\mu A$ & 24.33 & Yes & Present study \\
\hline \multirow[t]{2}{*}{ N. americanus } & 170.1 & $n A$ & 570.7 & No & Present study \\
\hline & & & ${ }^{\star}$ Partial agonist & & \\
\hline A. caninum & 50 & $\sim 100 \mathrm{nA}$ & ${ }^{*}$ Partial agonist & No & Choudhary et al., 2019 \\
\hline H. contortus & Non-functional & Non-functional & Non-functional & Non-functional & Charvet et al., 2018 \\
\hline C. elegans & 15.85 & $62.5 \pm 10 \mathrm{nA}$ & $\mathrm{n} / \mathrm{a}$ & No & Raymond et al., 2000 \\
\hline \multirow[t]{2}{*}{ C. elegans } & 55.4 & $n A-\mu A$ & 12.6 & $\mathrm{n} / \mathrm{a}$ & Ballivet et al., 1996 \\
\hline & & & ${ }^{\star}$ Partial agonist & & \\
\hline P. equorum & 6.4 & $\mu \mathrm{A}$ & 2.9 & $\mathrm{n} / \mathrm{a}$ & Charvet et al., 2018 \\
\hline A. suum & 5.9 & $n A-\mu A$ & 3.9 & Yes & Abongwa et al., 2016 \\
\hline
\end{tabular}

Surprisingly, despite being phylogenetically closer to $N$. americanus and A. caninum, A. ceylanicum ACR-16 receptor pharmacology more closely resembles that of ACR-16 from the clade III nematode A. suum. This is highlighted by large evoked current amplitudes, greater potency of nicotine than acetylcholine, and weak activation by oxantel on Ace- and Asu-ACR-16, but not on Nam- and Aca-ACR-16 (Abongwa et al., 2016). A limitation of our study was the use of a single, high concentration of the panel of anthelmintics to screen for agonist activity. These concentrations allowed us to compare maximal agonist activity, but did not permit the determination of competition or allosteric modulation.

\section{Homology Modeling}

We used homology modeling to determine if structural differences in the binding pocket may explain differences in the pharmacology of $A$. ceylanicum and N. americanus ACR16 receptors. Some differences in binding positions, but not binding energies of nicotine and acetylcholine were predictive of lower potency and efficacy on the Nam-ACR-16 receptor. The inability of ligands to bind deeply into the aromatic box and form hydrogen bonds with loop D of the complementary subunit has been associated with reduced channel activation for human AChRs (Celie et al., 2004; Blum et al., 2010). It is possible that the inability to dock the pyrimidine of nicotine fully into the binding pocket is related to its inability to produce maximal current responses; in vitro mutagenesis studies will be required to determine the binding partners involved.

Significant differences in binding energies were predicted for tetrahydropyrimidine binding, expected to occupy the same pocket (Bartos et al., 2006; Martin and Robertson, 2007). Ace-ACR-16 responded to pyrantel and oxantel in vitro, and both drugs docked into our in silico model with similar predicted energies and orientations. In contrast, Nam-ACR16 was much less responsive to pyrantel in vitro, and not at all to oxantel, and neither drug could be docked into the in silico model with a negative $\mathrm{kcal} / \mathrm{mol}$ (no bonds predicted to form). Compared to acetylcholine and nicotine, less is known regarding the intermolecular interactions required for tetrahydropyrimidine efficacy on AChRs. Pyrantel-induced activation is strongly associated with the presence of a glutamic acid in loop B (Bartos et al., 2006; Rayes et al., 2004) and a glutamine in loop D (Bartos et al., 2006). This loop D glutamine is also required for morantel, but not acetylcholine or oxantel binding to the $\alpha 7$ receptor (Bartos et al., 2009). Interestingly, all characterized ACR-16 subunits lack these residues, and instead possess an analogous loop D aspartic acid and loop B glycine (Positions 82 and 139 in the Figure 1 alignment, respectively). These differences in amino acid composition may explain the lack of efficacy of pyrantel and morantel, but do not explain differences between ACR16 receptors.

Nam-ACR-16 has an isoleucine in position 130 of the (-) complementary subunit that contributes to the binding pocket. In all oxantel-insensitive ACR-16s, this analogous residue points inwards to the binding pocket, whereas it points away from the pocket in oxantel-sensitive Ace- and Asu-ACR-16 models. This difference in orientation could reflect limitations of our models, but as a counterargument it accurately predicted acetylcholine binding as in the A. suum ACR-16 model (Zheng et al., 2016) as well as in crystallographic analysis of acetylcholine binding (Pan et al., 2012; Olsen et al., 2014). Changing this residue to the smaller valine in either Nam- or Cel-ACR-16 allowed more space for oxantel to bind and yielded stronger predicted binding energies.

One limitation to a putative role of a smaller residue in susceptibility to oxantel is that this position is a leucine in the human $\alpha-7$ AChR, for which oxantel is a weak partial agonist. Substitution of Ile130 with leucine in both Cel- and Nam-ACR16 also rescued predicted oxantel binding, albeit in a fashion comparable to Ile130 to valine. Yao et al. (2008) showed that loop E residues play a role in neonicotinoid selectivity and may rationalize differences in Ace- and Nam-ACR-16 anthelmintic binding in our models. Another limitation to a putative role of a smaller residue in susceptibility to oxantel is that Aca-ACR16 contains an inward facing Val130 and did not respond to oxantel. It is possible that oxantel currents are hidden by the small magnitude of current generated by this receptor, or that this extra space allows binding but not gating. Further studies using sitedirected mutagenesis on these receptors may shed light on the role of the unique species-related residues involved in differential anthelmintic efficacy. 
Increased space in this position alone is not likely to be a sufficient condition for determining oxantel sensitivity as the homology model of Tmu-ACR-16 also indicated the presence of an inward facing Ile130 residue, but oxantel is predicted to bind with high affinity. Trichuris spp. are paralyzed by oxantel, and our model of a putative Trichuris ACR-16 sequence also predicted strong ligand binding, despite the bulky side chain. However, the clade I Trichuris spp. are phylogenetically divergent from hookworms, and contain more sequence differences including the absence of a bulky histidine residue in loop $\mathrm{E}$, which provides greater space for oxantel binding in our model. Interestingly, this loop E histidine is also absent in the oxantel-sensitive Asu-ACR16 receptor (Abongwa et al., 2016).

Another unique characteristic of the putative Trichuris spp. ACR-16 receptors is the presence of an outward branching valine in place of a Met129 that branches into the aromatic box in the other ACR-16s. Furthermore, the human $\alpha-7$ sequence also has a valine at this position but oxantel is a partial agonist on this receptor. The $\delta$-sulfur of methionine acts as an electrophile for aromatic amino acids, forming methionine- $\pi$ interactions as strong as salt bridges and up to $\sim 6 \AA$ apart (Valley et al., 2012). It is possible that the presence of M129 conditionally restricts space for oxantel docking and introduces intra-subunit interactions that alter oxantel binding and activation. These differences in amino acid composition suggest that multiple species-specific residues play a role in selective oxantel sensitivity, and that Ile130 may play a secondary role in oxantel selectivity.

The relevance of differential tetrahydropyrimidine activity on ACR-16 receptors and its relationship to hookworm sensitivity to this drug class has intriguing implications. Richards et al. (1995) reported that $N$. americanus and A. ceylanicum are similarly paralyzed by pyrantel in vitro. Additionally, pyrantel and oxantel combination therapy has produced mixed reports in clearance of worms, and modest efficacy in reducing egg count in human hookworm infections (Rim et al., 1975; Moser et al., 2017). In contrast, in vivo studies with oxantel alone for Ancyostoma spp. or $N$. americanus infections indicate that it has no direct effect on the worms compared to high clearance levels against Trichuris spp. (Keiser et al., 2013). Interestingly, oxantel has been suggested to directly target $\mathrm{N}$-type acetylcholine receptors as the mechanism of anthelmintic activity (Martin et al., 2004). If ACR-16 is the primary target of oxantel, then our results provide a mechanism to explain the lack of in vivo efficacy against $N$. americanus. If this is the case, then identifying a Trichuris spp. ACR-16 receptor and determining its in vitro oxantel and pyrantel sensitivity profiles may be illuminating. In support of this, the preprint of a pharmacological profile of a T. suis ACR-16-like receptor was made available online after the submission of this manuscript that report super-agonism by oxantel compared to acetylcholine and modest partial agonism by pyrantel (Hansen et al., 2020).

\section{Levamisole}

In line with all published ACR-16 data, neither Ace- or NamACR-16 was directly activated by levamisole, the anthelmintic activity of which is strongly associated with L-type acetylcholine receptors (Lewis et al., 1980). Of note, the first report of ACR16 function indicated that levamisole was an antagonist of this receptor (Ballivet et al., 1996). Our results also show strong inhibition of acetylcholine responses by levamisole. ACR-16 knockout strains of $C$. elegans respond to levamisole slightly, but not significantly, less than wildtype worms (Touroutine et al., 2005); these authors did not rule out the possibility that ACR16 sensitivity to levamisole is redundant to, and masked by, the presence of L-AChRs. When the C. elegans L-type AChR was abolished by a null unc-29 allele, roughly $10 \%$ of worms were still paralyzed by exposure to levamisole (Duguet et al., 2016), suggesting a small but detectable contribution of a subset of levamisole-sensitive secondary targets. The significance of this interaction for the in vivo anthelmintic properties of levamisole is unclear, and we cannot discount the possibility that inhibition of ACR-16 receptors plays a role in its anthelmintic action.

\section{Conclusions}

Our aim was to characterize ACR-16 receptors from hookworms of humans and determine differences in function attributable to species specificity. We found sensitivity to acetylcholine and nicotine, the defining features of N-type AChRs, and furthermore suggest that a structural constraint in the binding pocket of $N$. americanus accounts for the failure of oxantel to activate the receptor, which warrants further investigation. Together with existing data from ACR-16 receptors of numerous nematodes, our data suggest a great level of variability in response profiles to anthelmintics even among closely related nematode species. These implications caution against generalizing functional results of ion channel drug targets from one nematode to another and highlight the importance of relating therapeutic treatment to the unique nature of each drug target.

\section{DATA AVAILABILITY STATEMENT}

The datasets presented in this study can be found in online repositories. The names of the repository/repositories and accession number(s) can be found below: https://www.ncbi.nlm. nih.gov/, MT163735; https://www.ncbi.nlm.nih.gov/, MT163736.

\section{ETHICS STATEMENT}

The animal study was reviewed and approved by McGill Animal Care Committee. All experiments were performed under the AUP \#2015-7758 issued by the McGill Animal Care Committee.

\section{AUTHOR CONTRIBUTIONS}

MK designed and performed the experiments and wrote the manuscript. TG and RB supervised the project and edited the manuscript. All authors provided critical feedback to create this manuscript.

\section{FUNDING}

This work was funded by Canadian Natural Sciences and Engineering Research Council Discovery grants awarded to TG and RB. NSERC award 210349. 


\section{REFERENCES}

Abongwa, M., Buxton, S. K., Courtot, E., Charvet, C. L., Neveu, C., McCoy, C. J., et al. (2016). Pharmacological profile of Ascaris suum ACR-16, a new homomeric nicotinic acetylcholine receptor widely distributed in Ascaris tissues. Br. J. Pharmacol. 173, 2463-2477. doi: 10.1111/bph.13524

Atchison, W. D., Geary, T. G., Manning, B., VandeWaa, E. A., and Thompson, D. P. (1992). Comparative neuromuscular blocking actions of levamisole and pyrantel-type anthelmintics on rat and gastrointestinal nematode somatic muscle. Toxicol. Appl. Pharmacol. 112, 133-143. doi: 10.1016/0041-008X(92) 90289-5

Ballivet, M., Alliod, C., Bertrand, S., and Bertrand, D. (1996). Nicotinic acetylcholine receptors in the nematode Caenorhabditis elegans. J. Mol. Biol. 258, 261-269. doi: 10.1006/jmbi.1996.0248

Barda, B., Ame, S. M., Ali, S. M., Albonico, M., Puchkov, M., Huwyler, J., et al. (2018). Efficacy and tolerability of moxidectin alone and in co-administration with albendazole and tribendimidine versus albendazole plus oxantel pamoate against Trichuris trichiura infections: a randomised, non-inferiority, singleblind trial. Lancet Infect. Dis. 18, 864-873. doi: 10.1016/S1473-3099(18)30 233-0

Bartos, M., Price, K. L., Lummis, S. C. R., Bouzat, C. (2009). Glutamine 57 at the complementary binding site face is a key determinant of morantel selectivity for $\alpha 7$ nicotinic receptors. J. Biol. Chem. 284, 21478-21487. doi: 10.1074/jbc.M109. 013797

Bartos, M., Rayes, D., and Bouzat, C. (2006). Molecular determinants of pyrantel selectivity in nicotinic receptors. Mol. Pharmacol. 70, 1307-1318. doi: 10.1124/ mol.106.026336

Bartsch, S. M., Hotez, P. J., Asti, L., Zapf, K. M., Bottazzi, M. E., Diemert, D. J., et al. (2016). The global economic and health burden of human hookworm infection. PLoS Negl. Trop. Dis. 10:e0004922. doi: 10.1371/journal.pntd.0004922

Behnke, J. M., Rose, R., and Garside, P. (1993). Sensitivity to ivermectin and pyrantel of Ancylostoma ceylanicum and Necator americanus. Int. J. Parasitol. 23, 945-952. doi: 10.1016/0020-7519(93)90061-3

Bennett, H. M., Lees, K., Harper, K. M., Jones, A. K., Sattelle, D. B., Wonnacott, S., et al. (2012). Xenopus laevis RIC-3 enhances the functional expression of the C. elegans homomeric nicotinic receptor, ACR-16, in Xenopus oocytes. J. Neurochem. 123, 911-918. doi: 10.1111/jnc.12013

Blum, A. J., and Hotez, P. J. (2018). Global "worming": climate change and its projected general impact on human helminth infections. PLoS Negl. Trop. Dis. 12:e0006370. doi: 10.1371/journal.pntd.0006370

Blum, A. P., Lester, H. A., and Dougherty, D. A. (2010). Nicotinic pharmacophore: the pyridine $\mathrm{N}$ of nicotine and carbonyl of acetylcholine hydrogen bond across a subunit interface to a backbone NH. Proc. Natl. Acad. Sci. U.S.A. 107, 13206-13211. doi: 10.1073/pnas.1007140107

Botero, D., and Castano, A. (1973). Comparative study of pyrantel pamoate, bephenium hydroxynaphthoate, and tetrachlorethylene in the treatment of Necator americanus infections. Am. J. Trop. Med. Hyg. 22, 45-52. doi: 10.4269/ ajtmh.1973.22.45

Boulin, T., Fauvin, A., Charvet, C. L., Cortet, J., Cabaret, J., Bessereau, J. L., et al. (2011). Functional reconstitution of Haemonchus contortus acetylcholine receptors in Xenopus oocytes provides mechanistic insights into levamisole resistance. Br. J. Pharmacol. 164, 1421-1432. doi: 10.1111/j.1476-5381.2011. 01420.x

Boulin, T., Gielen, M., Richmond, J. E., Williams, D. C., Paoletti, P., and Bessereau, J. L. (2008). Eight genes are required for functional reconstitution of the Caenorhabditis elegans levamisole-sensitive acetylcholine receptor. Proc. Natl. Acad. Sci. U.S.A. 105, 18590-18595. doi: 10.1073/pnas.08069 33105

Buxton, S. K., Charvet, C. L., Neveu, C., Cabaret, J., Cortet, J., Peineau, N., et al. (2014). Investigation of acetylcholine receptor diversity in a nematode parasite leads to characterization of tribendimidine-and derquantel-sensitive nAChRs. PLoS Pathog. 10:e1003870. doi: 10.1371/journal.ppat.1003870

Castro, P. D. J., Howell, S. B., Schaefer, J. J., Avramenko, R. W., Gilleard, J. S., and Kaplan, R. M. (2019). Multiple drug resistance in the canine hookworm Ancylostoma caninum: an emerging threat? Parasit. Vectors 12:576. doi: 10. 1186/s13071-019-3828-6

Celie, P. H. N., Rossum-Fikkert, S. E., van Dijk, W. J., van, Brejc, K., Smit, A. B., et al. (2004). Nicotine and carbamylcholine binding to nicotinic acetylcholine receptors as studied in AChBP crystal structures. Neuron 41, 907-914. doi: 10.1016/S0896-6273(04)00115-1

Charvet, C. L., Guégnard, F., Courtot, E., Cortet, J., and Neveu, C. (2018). Nicotinesensitive acetylcholine receptors are relevant pharmacological targets for the control of multidrug resistant parasitic nematodes. Int. J. Parasitol. Drugs Drug Resist. 8, 540-549. doi: 10.1016/j.ijpddr.2018.11.003

Choudhary, S., Tipton, J. G., Abongwa, M., Brewer, M. T., Chelladurai, J. J., Musselman, N., et al. (2019). Pharmacological characterization of a homomeric nicotinic acetylcholine receptor formed by Ancylostoma caninum ACR-16. Invertebr. Neurosci. 19:11. doi: 10.1007/s10158-019-0231-0

Courtot, E., Charvet, C. L., Beech, R. N., Harmache, A., Wolstenholme, A. J., Holden-Dye, L., et al. (2015). Functional characterization of a novel class of morantel-sensitive acetylcholine receptors in nematodes. PLoS Pathog. 11:e1005267. doi: 10.1371/journal.ppat.1005267

Cully, D. F., and Paress, P. S. (1991). Solubilization and characterization of a high affinity ivermectin binding site from Caenorhabditis elegans. Mol. Pharmacol. 40, 326-332.

Dougherty, D. A. (2008). Cys-loop neuroreceptors: structure to the rescue? Chem. Rev. 108, 1642-1653. doi: 10.1021/cr078207z

Duerr, J. S., Gaskin, J., and Rand, J. B. (2001). Identified neurons in C. elegans coexpress vesicular transporters for acetylcholine and monoamines. Am. J. Physiol. Physiol. 280, C1616-C1622. doi: 10.1152/ajpcell.2001.280.6.C1616

Duguet, T. B., Charvet, C. L., Forrester, S. G., Wever, C. M., Dent, J. A., Neveu, C., et al. (2016). Recent duplication and functional divergence in parasitic nematode levamisole-sensitive acetylcholine receptors. PLoS Negl. Trop. Dis. 10:e0004826. doi: 10.1371/journal.pntd.0004826

Garcia, E. G. (1976). Treatment for trichuriasis with oxantel. Am. J. Trop. Med. Hyg. 25, 914-915. doi: 10.4269/ajtmh.1976.25.914

Geary, T. G., and Thompson, D. P. (2001). Caenorhabditis elegans: how good a model for veterinary parasites? Vet. Parasitol. 101, 371-386. doi: 10.1016/ S0304-4017(01)00562-3

Grandemange, E., Claerebout, E., Genchi, C., and Franc, M. (2007). Field evaluation of the efficacy and the safety of a combination of oxantel/pyrantel/praziquantel in the treatment of naturally acquired gastrointestinal nematode and/or cestode infestations in dogs in Europe. Vet. Parasitol. 145, 94-99. doi: 10.1016/j.vetpar.2006.11.013

Hansen, T. V. A., Cirera, S., Neveu, C., Calloe, K., Klaerke, D. A., and Martin, R. J. (2020). The narrow-spectrum anthelmintic oxantel is a potent agonist of a novel acetylcholine receptor subtype in whipworms. bioRxiv [Preprint]. doi: 10.1101/2020.09.17.301192

Harrow, I. D., and Gration, K. A. F. (1985). Mode of action of the anthelmintics morantel, pyrantel and levamisole on muscle cell membrane of the nematode Ascaris suum. Pestic. Sci. 16, 662-672. doi: 10.1002/ps.2780160612

Hoagland, K. E., and Schad, G. A. (1978). Necator americanus and Ancylostoma duodenale: life history parameters and epidemiological implications of two sympatric hookworms of humans. Exp. Parasitol. 44, 36-49. doi: 10.1016/00144894(78)90078-4

Hochedez, P., and Caumes, E. (2007). Hookworm-related cutaneous larva migrans. J. Travel Med. 14, 326-333. doi: 10.1111/j.1708-8305.2007.00148.x

Hotez, P. (2008). Hookworm and poverty. Ann. N. Y. Acad. Sci. 1136, 38-44. doi: 10.1196/annals. 1425.000

Hotez, P. J. (2018). Human parasitology and parasitic diseases: heading towards 2050. Adv. Parasitol. 100, 29-38. doi: 10.1016/bs.apar.2018.03.002

Howe, K. L., Bolt, B. J., Shafie, M., Kersey, P., and Berriman, M. (2017). WormBase ParaSite- a comprehensive resource for helminth genomics. Mol. Biochem. Parasitol. 215, 2-10. doi: 10.1016/j.molbiopara.2016.11.005

Howes, H. L. Jr. (1972). Trans-1, 4, 5, 6-tetrahydro-2-(3-hydroxystyryl)-1-methyl pyrimidine (CP-14,445), a new antiwhipworm agent. Proc. Soc. Exp. Biol. Med. 139, 394-398. doi: 10.3181/00379727-139-36151

Humphries, D., Mosites, E., Otchere, J., Twum, W. A., Woo, L., Jones-Sanpei, H., et al. (2011). Epidemiology of hookworm infection in Kintampo North Municipality, Ghana: patterns of malaria coinfection, anemia, and albendazole treatment failure. Am. J. Trop. Med. Hyg. 84, 792-800. doi: 10.4269/ajtmh.2011. 11-0003

Kearse, M., Moir, R., Wilson, A., Stones-Havas, S., Cheung, M., Sturrock, S., et al. (2012). Geneious Basic: an integrated and extendable desktop software platform for the organization and analysis of sequence data. Bioinformatics 28, 1647-1649. doi: 10.1093/bioinformatics/bts199 
Keiser, J., Tritten, L., Silbereisen, A., Speich, B., Adelfio, R., and Vargas, M. (2013). Activity of oxantel pamoate monotherapy and combination chemotherapy against Trichuris muris and hookworms: revival of an old drug. PLoS Negl. Trop. Dis. 7:e2119. doi: 10.1371/journal.pntd.0002119

Keiser, J., and Utzinger, J. (2008). Efficacy of current drugs against soil-transmitted helminth infections: systematic review and meta-analysis. JAMA 299, 19371948. doi: 10.1001/jama.299.16.1937

Kopp, S. R., Kotze, A. C., McCarthy, J. S., and Coleman, G. T. (2007). High-level pyrantel resistance in the hookworm Ancylostoma caninum. Vet. Parasitol. 143, 299-304. doi: 10.1016/j.vetpar.2006.08.036

Krepel, H. P., Haring, T., Baeta, S., and Polderman, A. M. (1993). Treatment of mixed Oesophagostomum and hookworm infection: effect of albendazole, pyrantel pamoate, levamisole and thiabendazole. Trans. R. Soc. Trop. Med. Hyg. 87, 87-89. doi: 10.1016/0035-9203(93)90437-U

Lewis, J. A., Wu, C.-H., Berg, H., and Levine, J. H. (1980). The genetics of levamisole resistance in the nematode Caenorhabditis elegans. Genetics 95, 905-928.

Li, S., Huang, S., Bren, N., Noridomi, K., Dellisanti, C. D., Sine, S. M., et al. (2011). Ligand-binding domain of an $\alpha 7$-nicotinic receptor chimera and its complex with agonist. Nat Neurosci. 14, 1253-1259. doi: 10.1038/nn.2908

Lummis, S. C. R., Beene, D. L., Lee, L. W., Lester, H. A., Broadhurst, R. W., and Dougherty, D. A. (2005). Cis-trans isomerization at a proline opens the pore of a neurotransmitter-gated ion channel. Nature 438, 248-252. doi: 10.1038/ nature 04130

Martin, R. J., Clark, C. L., Trailovic, S. M., and Robertson, A. P. (2004). Oxantel is an N-type (methyridine and nicotine) agonist not an L-type (levamisole and pyrantel) agonist: classification of cholinergic anthelmintics in Ascaris. Int. J. Parasitol. 34, 1083-1090. doi: 10.1016/j.ijpara.2004.04.014

Martin, R. J., and Robertson, A. P. (2007). Mode of action of levamisole and pyrantel, anthelmintic resistance, E153 and Q57. Parasitology 134, 1093-1104. doi: 10.1017/S0031182007000029

Martin, R. J., Verma, S., Levandoski, M., Clark, C. L., Qian, H., Stewart, M., et al. (2005). Drug resistance and neurotransmitter receptors of nematodes: recent studies on the mode of action of levamisole. Parasitology 131, S71-S84. doi: 10.1017/S003118200500866

McKay, J. P., Raizen, D. M., Gottschalk, A., Schafer, W. R., and Avery, L. (2004). eat2 and eat-18 are required for nicotinic neurotransmission in the Caenorhabditis elegans pharynx. Genetics 166, 161-169. doi: 10.1534/genetics.166.1.161

Meldal, B. H. M., Debenham, N. J., De Ley, P., De Ley, I. T., Vanfleteren, J. R., Vierstraete, A. R., et al. (2007). An improved molecular phylogeny of the Nematoda with special emphasis on marine taxa. Mol. Phylogenet. Evol. 42, 622-636. doi: 10.1016/j.ympev.2006.08.025

Miledi, R., and Parker, I. (1984). Chloride current induced by injection of calcium into Xenopus oocytes. J. Physiol. 357, 173-183. doi: 10.1113/jphysiol.1984. sp015495

Moser, W., Ali, S. M., Ame, S. M., Speich, B., Puchkov, M., Huwyler, J., et al. (2016). Efficacy and safety of oxantel pamoate in school-aged children infected with Trichuris trichiura on Pemba Island, Tanzania: a parallel, randomised, controlled, dose-ranging study. Lancet Infect. Dis. 16, 53-60. doi: 10.1016/ S1473-3099(15)00271-6

Moser, W., Coulibaly, J. T., Ali, S. M., Ame, S. M., Amour, A. K., Yapi, R. B., et al. (2017). Efficacy and safety of tribendimidine, tribendimidine plus ivermectin, tribendimidine plus oxantel pamoate, and albendazole plus oxantel pamoate against hookworm and concomitant soil-transmitted helminth infections in Tanzania and Côte d'Ivoire: a randomised, controlled, single-blinded, noninferiority trial. Lancet Infect. Dis. 17, 1162-1171. doi: 10.1016/S1473-3099(17) 30487-5

Neveu, C., Charvet, C. L., Fauvin, A., Cortet, J., Beech, R. N., and Cabaret, J. (2010). Genetic diversity of levamisole receptor subunits in parasitic nematode species and abbreviated transcripts associated with resistance. Pharmacogenet. Genomics 20, 414-425. doi: 10.1097/FPC.0b013e328338ac8c

Nielsen, H., and Krogh, A. (1998). Prediction of signal peptides and signal anchors by a hidden Markov model. Proc. Int. Conf. Intell. Syst. Mol. Biol. 6, $122-130$.

Okulewicz, A. (2017). The impact of global climate change on the spread of parasitic nematodes. Ann. Parasitol. 63, 15-20. doi: 10.17420/ap6301.79

Olsen, J. A., Balle, T., Gajhede, M., Ahring, P. K., and Kastrup, J. S. (2014). Molecular recognition of the neurotransmitter acetylcholine by an acetylcholine binding protein reveals determinants of binding to nicotinic acetylcholine receptors. PLoS One 9:e91232. doi: 10.1371/journal.pone.0091232

Pan, J., Chen, Q., Willenbring, D., Yoshida, K., Tillman, T., Kashlan, O. B., et al. (2012). Structure of the pentameric ligand-gated ion channel ELIC cocrystallized with its competitive antagonist acetylcholine. Nat. Commun. 3:714. doi: 10.1038/ncomms1703

Pettersen, E. F., Goddard, T. D., Huang, C. C., Couch, G. S., Greenblatt, D. M., Meng, E. C., et al. (2004). UCSF Chimera-a visualization system for exploratory research and analysis. J. Comput. Chem. 25, 1605-1612. doi: 10. 1002/jcc.20084

Rayes, D., De Rosa, M. J., Bartos, M., and Bouzat, C. (2004). Molecular basis of the differential sensitivity of nematode and mammalian muscle to the anthelmintic agent levamisole. J. Biol. Chem. 279, 36372-36381. doi: 10.1074/ jbc.M403096200

Raymond, V., Mongan, N. P., and Sattelle, D. B. (2000). Anthelmintic actions on homomer-forming nicotinic acetylcholine receptor subunits: chicken $\alpha 7$ and ACR-16 from the nematode Caenorhabditis elegans. Neuroscience 101, 785-791. doi: 10.1016/S0306-4522(00)00279-7

Reynoldson, J. A., Behnke, J. M., Pallant, L. J., Macnish, M. G., Gilbert, F., Giles, S., et al. (1997). Failure of pyrantel in treatment of human hookworm infections (Ancylostoma duodenale) in the Kimberley region of north west Australia. Acta Trop. 68, 301-312. doi: 10.1016/S0001-706X(97)00106-X

Richards, J. C., Behnke, J. M., and Duce, I. R. (1995). In vitro studies on the relative sensitivity to ivermectin of Necator americanus and Ancylostoma ceylanicum. Int. J. Parasitol. 25, 1185-1191. doi: 10.1016/0020-7519(95)00036-2

Rienzo, M., Rocchi, A. R., Threatt, S. D., Dougherty, D. A., and Lummis, S. C. R. (2016). Perturbation of critical prolines in Gloeobacter violaceus ligand-gated ion channel (GLIC) supports conserved gating motions among Cys-loop receptors. J. Biol. Chem. 291, 6272-6280. doi: 10.1074/jbc.M115.694372

Rim, H. J., Won, C. Y., Lee, S. I., and Lim, J. K. (1975). Anthelmintic effect of oxantel pamoate and pyrantel pamoate suspension against intestinal nematode infestations. Korean J. Parasitol. 13, 97-101. doi: 10.3347/kjp.1975.13.2.97

Rozen, S., and Skaletsky, H. (2000). "Primer3 on the WWW for general users and for biologist programmers," in Bioinformatics Methods and Protocols. Methods in Molecular Biology ${ }^{T M}$, Vol. 132, eds S. Misener and S. A. Krawetz (Totowa, NJ: Humana Press), 365-386. doi: 10.1385/1-59259-192-2:365

Šali, A., and Blundell, T. L. (1993). Comparative protein modelling by satisfaction of spatial restraints. J. Mol. Biol. 234, 779-815. doi: 10.1006/jmbi.1993.1626

Schwarz, E. M., Hu, Y., Antoshechkin, I., Miller, M. M., Sternberg, P. W., and Aroian, R. V. (2015). The genome and transcriptome of the zoonotic hookworm Ancylostoma ceylanicum identify infection-specific gene families. Nat. Genet. 47:416. doi: $10.1038 /$ ng. 3237

Soukhathammavong, P. A., Sayasone, S., Phongluxa, K., Xayaseng, V., Utzinger, J., Vounatsou, P., et al. (2012). Low efficacy of single-dose albendazole and mebendazole against hookworm and effect on concomitant helminth infection in Lao PDR. PLoS Negl. Trop. Dis. 6:e1417. doi: 10.1371/journal.pntd.0001417

Speich, B., Ame, S. M., Ali, S. M., Alles, R., Huwyler, J., Hattendorf, J., et al. (2014). Oxantel pamoate-albendazole for Trichuris trichiura infection. N. Engl. J. Med. 370, 610-620. doi: 10.1056/NEJMoa1301956

Tang, Y. T., Gao, X., Rosa, B. A., Abubucker, S., Hallsworth-Pepin, K., Martin, J., et al. (2014). Genome of the human hookworm Necator americanus. Nat. Genet. 46, 261-269. doi: 10.1038/ng.2875

Touroutine, D., Fox, R. M., Von Stetina, S. E., Burdina, A., Miller, D. M. III, and Richmond, J. E. (2005). acr-16 encodes an essential subunit of the levamisoleresistant nicotinic receptor at the Caenorhabditis elegans neuromuscular junction. J. Biol. Chem. 280, 27013-27021. doi: 10.1074/jbc.M502818200

Traub, R. J. (2013). Ancylostoma ceylanicum, a re-emerging but neglected parasitic zoonosis. Int. J. Parasitol. 43, 1009-1015. doi: 10.1016/j.ijpara.2013.07.006

Tritten, L., Braissant, O., and Keiser, J. (2012). Comparison of novel and existing tools for studying drug sensitivity against the hookworm Ancylostoma ceylanicum in vitro. Parasitology 139, 348-357. doi: 10.1017/ S0031182011001934

Tritten, L., Silbereisen, A., and Keiser, J. (2011). In vitro and in vivo efficacy of monepantel (AAD 1566) against laboratory models of human intestinal nematode infections. PLoS Negl. Trop. Dis. 5:e1457. doi: 10.1371/journal.pntd. 0001457

Trott, O., and Olson, A. J. (2010). AutoDock Vina: improving the speed and accuracy of docking with a new scoring function, efficient optimization, 
and multithreading. J. Comput. Chem. 31, 455-461. doi: 10.1002/jcc. 21334

Valley, C. C., Cembran, A., Perlmutter, J. D., Lewis, A. K., Labello, N. P., Gao, J., et al. (2012). The methionine-aromatic motif plays a unique role in stabilizing protein structure. J. Biol. Chem. 287, 34979-34991. doi: 10.1074/jbc.M112. 374504

Weaver, H. J., Hawdon, J. M., and Hoberg, E. P. (2010). Soil-transmitted helminthiases: implications of climate change and human behavior. Trends Parasitol. 26, 574-581. doi: 10.1016/j.pt.2010.06.009

Williamson, S. M., Robertson, A. P., Brown, L., Williams, T., Woods, D. J., Martin, R. J., et al. (2009). The nicotinic acetylcholine receptors of the parasitic nematode Ascaris suum: formation of two distinct drug targets by varying the relative expression levels of two subunits. PLoS Pathog. 5:e1000517. doi: 10.1371/journal.ppat.1000517

World Health Organization (2012). Soil-transmitted Helminthiases: Eliminating Soil-transmitted Helmnthiases as a Public Health Problem in Children: Progress Report 2001-2010 and Strategic Plan 2011-2020. Geneva: World Health Organization.

World Health Organization (2020). 2030 Targets for Soil-transmitted Helminthiases Control Programmes. Geneva: World Health Organization.
Yao, X., Song, F., Chen, F., Zhang, Y., Gu, J., Liu, S., et al. (2008). Amino acids within loops $\mathrm{D}, \mathrm{E}$ and $\mathrm{F}$ of insect nicotinic acetylcholine receptor $\beta$ subunits influence neonicotinoid selectivity. Insect Biochem. Mol. Biol. 38, 834-840. doi: 10.1016/j.ibmb.2008.05.009

Zheng, F., Robertson, A. P., Abongwa, M., Yu, E. W., and Martin, R. J. (2016). The Ascaris suum nicotinic receptor, ACR-16, as a drug target: four novel negative allosteric modulators from virtual screening. Int. J. Parasitol. Drugs Drug Resist. 6, 60-73. doi: 10.1016/j.ijpddr.2016. 02.001

Conflict of Interest: The authors declare that the research was conducted in the absence of any commercial or financial relationships that could be construed as a potential conflict of interest.

Copyright (C) 2020 Kaji, Geary and Beech. This is an open-access article distributed under the terms of the Creative Commons Attribution License (CC BY). The use, distribution or reproduction in other forums is permitted, provided the original author(s) and the copyright owner(s) are credited and that the original publication in this journal is cited, in accordance with accepted academic practice. No use, distribution or reproduction is permitted which does not comply with these terms. 